\title{
The hypotensive effect of activated apelin receptor is correlated with
}

\section{$\beta$-arrestin recruitment}

Élie Besserer-Offroy ${ }^{\mathrm{a}, \mathrm{c}, \mathrm{ORCID} \text { ID }}$, Patrick Bérubéa,c, Jérôme Côtéa,c, Alexandre Murza ${ }^{\mathrm{a}, \mathrm{c}}$, Jean-Michel Longpré $^{\mathrm{a}, \mathrm{c}}$, Robert Dumaine ${ }^{\mathrm{a}}$, Olivier Lesur ${ }^{\mathrm{b}, \mathrm{c}}$, Mannix Auger-Messier ${ }^{\mathrm{b}, \text { ORCID ID }}$, Richard Leduc $^{\mathrm{a}, \mathrm{c}, \mathrm{ORCID} \text { ID }}$, Éric Marsault $\mathrm{a}^{\mathrm{a}, \mathrm{c}, *, \mathrm{ORCID} \text { ID }}$, Philippe Sarret $\mathrm{a}^{\mathrm{a}, \mathrm{c} *}$

\section{Affiliations}

${ }^{a}$ Department of Pharmacology-Physiology, Faculty of Medicine and Health Sciences, Université de Sherbrooke, Sherbrooke, Québec, CANADA J1H 5N4

${ }^{b}$ Department of Medicine, Faculty of Medicine and Health Sciences, Université de Sherbrooke, Sherbrooke, Québec, CANADA J1H 5N4

c Institut de pharmacologie de Sherbrooke, Université de Sherbrooke, Sherbrooke, Québec, CANADA J1H 5N4

e-mail addresses

Elie.Besserer-Offroy@USherbrooke.ca （ÉBO); Patrick.Berube@USherbrooke.ca （PB);

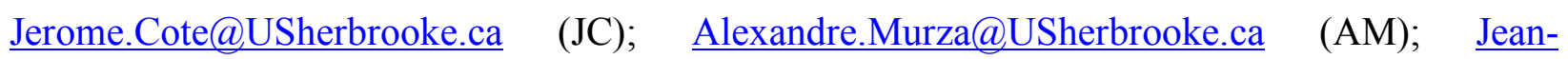
Michel.Longpre@USherbrooke.ca $\quad$ (JML); $\quad$ Robert.Dumaine@USherbrooke.ca $\quad(\mathrm{RD})$; Olivier.Lesur@USherbrooke.ca （OL); Mannix.Auger-Messier@USherbrooke.ca （MAM); Richard.Leduc@USherbrooke.ca $\quad$ (RL); $\quad$ Eric.Marsault@USherbrooke.ca $\quad$ (EM); Philippe.Sarret@USherbrooke.ca (PS) 
This is the accepted (postprint) version of the following article: Besserer-Offroy É, et al. (2018), Pharmacol Res. doi: 10.1016/j.phrs.2018.02.032, which has been accepted and published in its final form at https://www.sciencedirect.com/science/article/pii/S1043661817313804

\section{Corresponding Authors}

*To whom correspondence should be addressed:

Philippe Sarret, Ph.D.; Philippe.Sarret@USherbrooke.ca; Tel. +1 (819) 821-8000 ext. 72554

Éric Marsault, Ph.D.; Eric.Marsault@USherbrooke.ca; Tel. +1 (819) 821-8000 ext. 72433

Department of Pharmacology-Physiology, Faculty of Medicine and Health Sciences, Institut de pharmacologie de Sherbrooke, Université de Sherbrooke, Sherbrooke, Québec, CANADA J1H $5 \mathrm{~N} 4$

Abbreviations used: 7TMR, seven transmembrane receptor; Akt, protein kinase B; APJ, apelin receptor; $\beta$ arr, $\beta$ arrestin; BRET, bioluminescence resonance energy transfer; cAMP, cyclic adenosine monophosphate; ERK1/2, extracellular regulated kinase 1/2; GPCR, G protein-coupled receptor; i.m., intramuscular; i.v., intravenous; MABP, mean arterial blood pressure; MAPK, mitogen-activated protein kinase; NO, nitric oxide; PI3K, phosphoinisitide 3 kinase; PTX, pertussis toxin; RE, relative efficacy; TR-FRET, time-resolved fluorescence resonance energy transfer.

(c) 2018. This manuscript version is made available under the license http://creativecommons.org/licenses/by-nc-nd/4.0/ 
This is the accepted (postprint) version of the following article: Besserer-Offroy É, et al. (2018), Pharmacol Res. doi: 10.1016/j.phrs.2018.02.032, which has been accepted and published in its final form at https://www.sciencedirect.com/science/article/pii/S1043661817313804

\begin{abstract}
The apelinergic system is an important player in the regulation of both vascular tone and cardiovascular function, making this physiological system an attractive target for drug development for hypertension, heart failure and ischemic heart disease. Indeed, apelin exerts a positive inotropic effect in humans whilst reducing peripheral vascular resistance. In this study, we investigated the signaling pathways through which apelin exerts its hypotensive action. We synthesized a series of apelin-13 analogs whereby the C-terminal $\mathrm{Phe}^{13}$ residue was replaced by natural or unnatural amino acids. In HEK293 cells expressing APJ, we evaluated the relative efficacy of these compounds to activate $G \alpha_{i 1}$ and $G \alpha_{o A}$ G-proteins, recruit $\beta$-arrestins 1 and 2 ( $\beta$ arrs), and inhibit cAMP production. Calculating the transduction ratio for each pathway allowed us to identify several analogs with distinct signaling profiles. Furthermore, we found that these analogs delivered i.v. to Sprague-Dawley rats exerted a wide range of hypotensive responses. Indeed, two compounds lost their ability to lower blood pressure, while other analogs significantly reduced blood pressure as apelin-13. Interestingly, analogs that did not lower blood pressure were less effective at recruiting ßarrs. Finally, using Spearman correlations, we established that the hypotensive response was significantly correlated with $\beta$ arr recruitment but not with G proteindependent signaling. In conclusion, our results demonstrated that the $\beta$ arr recruitment potency is involved in the hypotensive efficacy of activated APJ.
\end{abstract}

Keywords: G Protein-Coupled Receptor (GPCR); G Protein; $\beta$-arrestin; Apelin receptor; Hypotension; Blood Pressure

Chemical compounds studied in this article: [Pyr ${ }^{1}$-apelin-13 (PubChem CID: 25085173)

(C) 2018. This manuscript version is made available under the CC-BY-NC-ND 4.0 license http://creativecommons.org/licenses/by-nc-nd/4.0/ 
This is the accepted (postprint) version of the following article: Besserer-Offroy É, et al. (2018), Pharmacol Res. doi: 10.1016/j.phrs.2018.02.032, which has been accepted and published in its final form at https://www.sciencedirect.com/science/article/pii/S1043661817313804

\section{Graphical Abstract}

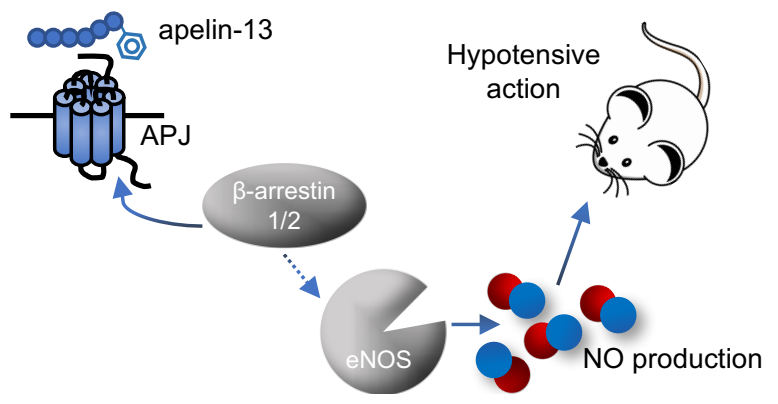

(c) 2018. This manuscript version is made available under the CC-BY-NC-ND

4.0 license http://creativecommons.org/licenses/by-nc-nd/4.0/ 
This is the accepted (postprint) version of the following article: Besserer-Offroy É, et al. (2018), Pharmacol Res. doi: 10.1016/j.phrs.2018.02.032, which has been accepted and published in its final form at https://www.sciencedirect.com/science/article/pii/S1043661817313804

\section{Introduction}

The apelin receptor (angiotensin receptor-like 1, APJ) is a seven transmembrane receptor (7TMR) that belongs to the class A peptidergic G protein-coupled receptors (GPCR) superfamily [1]. The endogenous ligands of APJ are the different isoforms of apelin (namely apelin-13, -17, and -36) [2] as well as the recently discovered ELABELA/Toddler [3]. The apelinergic axis is known to be widely distributed throughout the body, both in the central nervous system and at the periphery [4,5]. Peripherally, components of the apelin/APJ system are mainly expressed in the lungs, kidneys, pancreas as well as in the cardiovascular system [6]. Recently, the apelinergic system has been highlighted as a potential and promising target for drug development [7]. Indeed, modulating APJ signaling can be considered for the treatment of diabetes, obesity, cancer, and HIV infection [4]. However, the most important role of the apelin-APJ axis remains associated to its cardiovascular actions. Indeed, apelin peptides act as potent regulators of vascular function and exert one of the most powerful positive inotropic actions [8]. Accordingly, the apelin-APJ axis is widely distributed within the cardiovascular system, being expressed on endothelial cells, vascular smooth muscle cells and cardiomyocytes [9]. In preclinical models, APJ activation induces a significant drop in mean arterial blood pressure (MABP), reduces ventricular preload and afterload, increases myocardial contractility, and decreases angiotensin II-induced myocardial hypertrophy and fibrosis (for review see [10,11]). In rodents, the hypotensive actions of apelin-13 and apelin-17 are blocked by a pretreatment with L-NAME, a nitric oxide (NO) synthase inhibitor [12]. These beneficial/protective effects of apelin are paralleled in healthy volunteers and in chronic heart failure patients, in whom an intravenous (i.v.) injection of apelin-13 induces a vasodilation of coronary and peripheral blood vessels leading to a lowering of MABP, while increasing the cardiac output [13,14]. In support of the role of the apelin/APJ system in (C) 2018. This manuscript version is made available under the CC-BY-NC-ND 4.0 license http://creativecommons.org/licenses/by-nc-nd/4.0/ 
This is the accepted (postprint) version of the following article: Besserer-Offroy É, et al. (2018), Pharmacol Res. doi: 10.1016/j.phrs.2018.02.032, which has been accepted and published in its final form at https://www.sciencedirect.com/science/article/pii/S1043661817313804

cardiovascular function and pathology, plasma levels of apelin are markedly decreased in patients with chronic heart failure and failing human hearts also exhibit altered apelin and APJ gene expression patterns $[15,16]$.

At the cellular level, activation of APJ triggers several intracellular signaling pathways such as the activation of the Ga $\alpha_{\mathrm{i} / \mathrm{o}}$ pathway leading to inhibition of adenylate cyclase and a lowering of cAMP production [5]. Apelin-13 binding to APJ also induces the phosphorylation of the mitogenactivated protein kinase (MAPK) ERK1/2 by a Ga $\alpha_{\mathrm{i} /}$-dependent mechanism since this effect is blocked by a pretreatment with pertussis toxin (PTX) [17]. APJ activation further induces the recruitment of both $\beta$-arrestins 1 and 2 ( $\beta$ arrs), leading to receptor internalization $[18,19]$. Interestingly, intracellular trafficking routes seem to be agonist-dependent with, on the one hand, apelin-13 and -17, which induce a transient interaction between APJ and $\beta$ arr, and on the other hand, apelin-36, which displays a long lasting APJ/ßarr interaction [20].

Structure-activity relationship (SAR) and alanine-scan have highlighted that the N-terminal amino acids of apelin-13 (i.e. $\mathrm{Arg}^{2}-\mathrm{Pro}^{3}-\mathrm{Arg}^{4}-\mathrm{Leu}^{5}$ ) are involved in binding to APJ and activation of the $\mathrm{Ga}_{\mathrm{i} / \mathrm{o}}$ signaling pathway [5]. However, the C-terminal of apelin plays a crucial role in modulating APJ internalization and $\beta$ arr recruitment as well as being responsible for the APJ-dependent hypotensive response [18,21]. Indeed, the truncation of the C-terminal Phe residue or its replacement by Ala in apelin-13 or apelin-17 results in an impairment of the MABP lowering effect of these compounds [22]. Accordingly, we recently published that the substitution of Phe ${ }^{13}$ by unnatural amino acids induces changes in cAMP production and also affects the hypotensive action of these C-terminal modified apelin-13 analogs [19]. Herein, we examined the APJ signaling profile of a series of C-terminal modified analogs by studying their ability to activate $\mathrm{G \alpha}_{\mathrm{i}}, \mathrm{G} \alpha_{\mathrm{OA}}$, inhibit cAMP production, and recruit $\beta$ arrs. We further monitored the potency of these (c) 2018. This manuscript version is made available under the license http://creativecommons.org/licenses/by-nc-nd/4.0/ 
This is the accepted (postprint) version of the following article: Besserer-Offroy É, et al. (2018), Pharmacol Res. doi: 10.1016/j.phrs.2018.02.032, which has been accepted and published in its final form at https://www.sciencedirect.com/science/article/pii/S1043661817313804

compounds to elicit changes in MABP in rodents. To pair APJ receptor activity with its physiological effects, we finally applied the Black and Leff operational model to correlate the drop in MABP with a specific signaling signature. 


\section{Materials and methods}

\subsection{Materials}

All compounds including apelin-13 were synthesized by us as previously described [19]. Coelenterazine 400A (DeepBlueC) was purchased from Gold Biotechnology Inc. (St. Louis, MO, USA). DMEM, HEPES (4-(2-hydroxyethyl)-1-piperazineethanesulfonic acid), Penicillinstreptomycin-glutamine and fetal bovine serum (FBS) were obtained from Wisent (St. Bruno, QC, Canada), Opti-MEM was acquired from Invitrogen (Burlington, ON, Canada). Lance Ultra cAMP assay kit was purchased from Perkin Elmer (Montréal, QC, Canada).

\subsection{Plasmids and constructs}

Using an InFusion advantage PCR cloning kit (Clontech Laboratories, Mountain View, CA, USA), the hAPJ construct was inserted into the pIREShygro3-GFP10 vector as previously described [18]. The plasmids encoding RlucII- $\beta$-arrestin 1 or 2 [23], GaoA-RlucII [24], Gai1-RlucII, GFP10-G $\gamma 1$, and GFP10-G $\gamma 2$ [25] were kindly provided by Dr. Michel Bouvier. The cDNA encoding the human $\mathrm{G}_{\beta 1}$ subunit was obtained from the Missouri S\&T cDNA Resource Center (Rolla, MO, USA). All constructs were verified by DNA sequencing.

\subsection{Cell culture and transfections}

HEK293 QBI cells (CRL-1573, from ATCC) were cultured in DMEM containing 20 mM HEPES, 10\% FBS, penicillin (100 U/mL), streptomycin $(100 \mu \mathrm{g} / \mathrm{mL})$, and glutamine $(2 \mathrm{mM})$ under $5 \%$ $\mathrm{CO} 2$ at $37^{\circ} \mathrm{C}$ in a humidified atmosphere. Cells were used between passage numbers 4 to 25 . For the transient expression of recombinant proteins, T75 flasks were seeded with $3 \times 10^{6}$ cells, and $24 \mathrm{~h}$ later, the cells were transfected using PEI as previously described [26].

(C) 2018. This manuscript version is made available under the CC-BY-NC-ND 4.0 license http://creativecommons.org/licenses/by-nc-nd/4.0/ 
This is the accepted (postprint) version of the following article: Besserer-Offroy É, et al. (2018), Pharmacol Res. doi: 10.1016/j.phrs.2018.02.032, which has been accepted and published in its final form at https://www.sciencedirect.com/science/article/pii/S1043661817313804

\subsection{BRET assays}

To monitor direct $\mathrm{G}$ protein activation, we used the following biosensor couples: $\mathrm{G} \alpha_{\mathrm{oA}}-\mathrm{R} l \mathrm{lucII}$, GFP10-G $\gamma_{1}$, and G $\beta 1$ [24] or G $\alpha_{\mathrm{i} 1}-\mathrm{RlucII}, \mathrm{GFP} 10-\mathrm{G} \gamma_{2}$, and $\mathrm{G} \beta_{1}$ [25]. G protein biosensors and the hAPJ receptor were transfected into HEK293 QBI cells. At 24 h post-transfection, the cells were detached with trypsin-EDTA and plated (50,000 cells/well) in white opaque 96 -well plates (BD Falcon, Corning, NY, USA). At 48 h post-transfection, the cells were washed once with PBS, and $90 \mu \mathrm{L}$ of HBSS containing $20 \mathrm{mM}$ HEPES was then added. Ligands were added at increasing concentrations for $10 \mathrm{~min}$ followed by coelenterazine 400A $(5 \mu \mathrm{M})$. BRET ${ }^{2}$ measurements were collected in the 400 to $450 \mathrm{~nm}$ window (Rluc) and in the 500 to $550 \mathrm{~nm}$ window (GFP10) using the BRET $^{2}$ filter set on a GENios Pro plate reader (Tecan, Durham, NC, USA). The BRET ${ }^{2}$ ratio was determined as the light emitted by the acceptor GFP10 over the light emitted by the donor Rluc. The monitoring of $\beta$ arr recruitment was done by the transient transfection of HEK293 QBI cells with plasmids containing cDNAs encoding hAPJ-GFP10 and Rluc- $\beta$-arrestin 1 or 2 . The same protocol as the one used for $\mathrm{G}$ protein activation was then used.

\subsection{Lance Ultra cAMP assay}

The Lance Ultra cAMP assay was performed according to the manufacturer's recommendations as previously described [19]. Briefly, 1,000 cells per well (384-well shallow well plate) were treated with increasing concentrations of compounds for $30 \mathrm{~min}$ in the presence of $1 \mu \mathrm{M}$ forskolin. cAMP-tracer and anti-cAMP-Cryptate were added for at least $1 \mathrm{~h}$. The plates were read on a GENios Pro plate reader with HTRF filters (excitation at $320 \mathrm{~nm}$ and emission at 620 and 665 $\mathrm{nm})$. The TR-FRET ratio was determined as the fluorescence of the acceptor $(665 \mathrm{~nm})$ over the fluorescence of the donor $(620 \mathrm{~nm})$.

(C) 2018. This manuscript version is made available under the CC-BY-NC-ND 4.0 license http://creativecommons.org/licenses/by-nc-nd/4.0/ 
This is the accepted (postprint) version of the following article: Besserer-Offroy É, et al. (2018), Pharmacol Res. doi: 10.1016/j.phrs.2018.02.032, which has been accepted and published in its final form at https://www.sciencedirect.com/science/article/pii/S1043661817313804

\subsection{Animal procedures}

All animal procedures were approved by the Ethical and Animal Care Committee of the Université de Sherbrooke and were in accordance with policies and directives of the Canadian Council on Animal Care. Furthermore, all animal studies comply with both the ARRIVE Guidelines (http://www.nc3rs.org.uk/page.asp?id=1357) and the National Institutes of Health guide for the care and use of laboratory animals. Adult male (250-300g) Sprague-Dawley rats (Charles River Laboratories, St-Constant, Québec, Canada) were maintained on a $12 \mathrm{~h}$ light/dark cycle with access to food and water ad libitum. Rats were acclimatized for 4 days to the animal facility prior to studies.

\subsubsection{Blood pressure measurement}

Male Sprague-Dawley rats were anesthetized with a mixture of ketamine/xylazine $(87: 13 \mathrm{mg} / \mathrm{kg}$ i.m.) and placed on a heating pad. Then, systolic, diastolic, and mean arterial pressure were measured every 30 seconds by the tail-cuff method, using the CODA Blood Pressure System (Kent Scientific Co., Connecticut, USA). When the blood pressure was stabilized (five consecutive measure with less than 5\% variability), saline, apelin-13, or analogs was injected via the tail vein. Blood pressure measurements were acquired for seven minutes following compound delivery. Data used for Fig.3A were published, in part, in reference [19]. For the present study, the number of rats per dose of apelin-13 was increased and the dose of $10 \mathrm{mg} / \mathrm{kg}$ was added in order to fit a dose response curve.

\subsection{Data analysis for receptor activation parameters: $E C_{50}$ and $\log \left(\tau / K_{A}\right)$}

Each data set was normalized to the maximal response triggered by apelin-13, all values are expressed as the mean \pm S.E.M. of at least three different experiments, which were each performed (C) 2018. This manuscript version is made available under the CC-BY-NC-ND 4.0 license http://creativecommons.org/licenses/by-nc-nd/4.0/ 
This is the accepted (postprint) version of the following article: Besserer-Offroy É, et al. (2018), Pharmacol Res. doi: 10.1016/j.phrs.2018.02.032, which has been accepted and published in its final form at https://www.sciencedirect.com/science/article/pii/S1043661817313804

in triplicate. $\mathrm{EC}_{50}$ values were obtained from normalized data and determined as the concentration of ligand showing $50 \%$ of activation. The data were calculated using concentration-response three parameters non-linear regression of GraphPad Prism 6 (La Jolla, CA, USA).

The Black and Leff operational model describing receptor activation [27] was used to determine the transduction coefficient $\left(\frac{\tau}{K_{A}}\right)$ for each agonist using eq. (3), which is derived from the standard operational model equation, given by eq. (1):

$$
E=\frac{E_{m} \times[A]^{n} \times \tau^{n}}{[A]^{n} \times \tau^{n}+\left([A]+K_{A}\right)^{n}}
$$

Dividing above and below by $K_{A}$ gave the $\left(\frac{\tau}{K_{A}}\right)$ ratio, as depicted in eq. (2):

$$
E=\frac{E_{m} \times[A]^{n} \times\left(\frac{\tau}{K_{A}}\right)^{n}}{[A]^{n} \times\left(\frac{\tau}{K_{A}}\right)^{n}+\left(\frac{[A]}{K_{A}}+1\right)^{n}}
$$

Dividing the member of eq. (2) by $[A]^{\mathrm{n}} \times\left(\frac{\tau}{\mathrm{K}_{\mathrm{A}}}\right)^{\mathrm{n}}$ simplified the equation and gave eq. (3):

$$
E=\frac{E_{m}}{1+\left(\frac{\left[\frac{[A]}{K_{A}}+1\right.}{[A] \times\left(\frac{\tau}{K_{A}}\right)}\right)^{n}}
$$

In eq. (3), $E$ is the effect triggered by the ligand, $[A]$ is the concentration of ligand, $E_{m}$ represents the maximum response of the system (this is not the same as the $E_{\max }$, which represents the maximal response of the ligand), $n$ is the transducer slope that links occupancy to response (this is not the same as the Hill slope derived from logistic curve fitting, but these two parameters are closely related [28]), $K_{A}$ depicts the functional equilibrium dissociation constant, and $\tau$ denotes the operational agonist's efficacy. $E_{m}$ and $n$ are specific of the cell, they are thus shared by all agonists; whereas, $\tau$ and $K_{A}$ are specific of the ligand.

(C) 2018. This manuscript version is made available under the CC-BY-NC-ND 4.0 license http://creativecommons.org/licenses/by-nc-nd/4.0/ 
Fitting experimental data to eq. (3) could result in multiple combinations of $\tau$ and $K_{A}$, therefore, the transduction coefficient, defined by eq. (4), was used as a parameter to define the agonism for a given pathway at a given receptor:

$$
\text { Transduction coefficient }=\log \left(\frac{\tau}{K_{A}}\right)
$$

To eliminate the observational and system bias, ligand activity at a given pathway was divided by the activity of the reference compound, apelin-13 (APE), for the same pathway using eq. (5):

$$
\Delta \log \left(\frac{\tau}{K_{A}}\right)=\log \left(\frac{\tau}{K_{A}}\right)_{L I G}-\log \left(\frac{\tau}{K_{A}}\right)_{A P E}
$$

The relative efficacy of an agonist toward a given pathway, relative to the reference compound APE, was calculated as the anti-logarithm of the $\Delta \log \left(\frac{\tau}{K_{A}}\right)$ by eq. (6):

$$
\text { Relative efficacy }(R E)=10^{\Delta \log \left(\frac{\tau}{K_{A}}\right)}
$$

The standard error of the mean (S.E.M.) of the transduction coefficient $\log \left(\frac{\tau}{K_{A}}\right)$ was calculated by using eq. (7):

$$
S . E . M \cdot \log \left(\frac{\tau}{K_{A}}\right)=\frac{\sigma}{\sqrt{n}}
$$

In eq. (7), $\sigma$ represents the standard deviation calculated from each separate experiment and $n$ is the number of separate experiment performed.

Eq. (8) was used to calculate S.E.M. for the $\Delta \log \left(\frac{\tau}{K_{A}}\right)$ to avoid the propagation of the error during the subtraction step used to calculate the normalized transduction coefficient: 


$$
\text { S.E.M. }{ }_{\Delta \log \left(\frac{\tau}{K_{A}}\right)}=\sqrt{\left(S \cdot E \cdot M \cdot \log \left(\frac{\tau}{K_{A}}\right)_{L I G}\right)^{2}-\left(S \cdot E \cdot M \cdot \log \left(\frac{\tau}{K_{A}}\right)_{A P E}\right)^{2}}
$$

Standard parameters describing ligand-induced receptor activation (namely $\mathrm{EC}_{50}$ and $E_{\max }$ ) are closely related with the Black and Leff operational model of receptor activation. $\mathrm{EC}_{50}$ is linked to it by eq. (9):

$$
\mathrm{EC}_{50}=\frac{K_{A}}{\left(2+\tau^{n}\right)^{\frac{1}{n}}-1}
$$

and $E_{\max }$ by eq. (10):

$$
E_{\max }=\frac{E_{m} \tau^{n}}{1+\tau^{n}}
$$

\subsection{Data and statistical analyses for the in vivo procedures}

The $\mathrm{ED}_{50}$ value of the hypotensive effect of apelin-13 was determined as the concentration of apelin-13 showing $50 \%$ of the maximal hypotensive response. Each data point on the doseresponse curve represents the maximal hypotensive response of each dose of apelin-13. The data were calculated using dose-response three parameters non-linear regression of GraphPad Prism 6. Statistical analyses were performed using GraphPad Prism 6 and are described in the figure legend when applicable. A value was considered statistically significant when $p<0.05$. 
This is the accepted (postprint) version of the following article: Besserer-Offroy É, et al. (2018), Pharmacol Res. doi: 10.1016/j.phrs.2018.02.032, which has been accepted and published in its final form at https://www.sciencedirect.com/science/article/pii/S1043661817313804

\section{Results and discussion}

\subsection{Chemical modification of the Phe ${ }^{13}$ residue results in significant changes in APJ receptor binding and signaling}

Before assessing the signaling pathways activated by apelin-13 and its C-terminal modified analogs (structures of the analogs are presented in Scheme 1), we first characterized their binding affinities on the human APJ receptor expressed in HEK293 cells. IC 50 values for each apelin-13 analog are summarized in Table 1 . The $\mathrm{IC}_{50}$ of the endogenous reference compound apelin-13 was $1.2 \mathrm{nM}$ while some tested analogs carrying unnatural amino acids (compounds $\mathbf{3}, \mathbf{5}$, $\mathbf{6}$, and $\mathbf{8}$ ) exhibited higher affinities ranging from 0.02 to $0.48 \mathrm{nM}$. Other C-terminally modified analogs were found to have lower affinities when compared to apelin-13 (compounds 2, 4, 7, 9, and 10; with $\mathrm{IC}_{50}$ ranging from 6.1 to $68.2 \mathrm{nM}$ ). These results are in accordance with previous alanine and D-amino acid scanning data, suggesting that modification of the N-terminal region (i.e. $\mathrm{Arg}^{2}$-Pro ${ }^{3}$ $\mathrm{Arg}^{4}-\mathrm{Leu}^{5}$ ) as well as C-terminal residue substitutions significantly affect apelin-13 binding to APJ $[5,18,19]$.

To dissect the signaling pathways engaged by this series of apelin-13 analogs, we first assessed the ability of these compounds to activate $\mathrm{G} \alpha_{\mathrm{i} / \mathrm{o}}$ in HEK293 cells transiently overexpressing the APJ receptor. To this end, we used inhibition of the forskolin-induced cAMP production as an endpoint (Table 1 and Fig. 1A). We then monitored the activation of both the $\mathrm{G} \alpha_{\mathrm{i} 1}$ and the $\mathrm{G} \alpha_{\mathrm{OA}}$ pathways at the direct $\mathrm{G}$ protein level. Activation of $\mathrm{G \alpha}_{\mathrm{i} 1}$ by APJ was determined using a BRETbased assay by measuring the dissociation between $\mathrm{G} \alpha_{\mathrm{i} 1}$-RlucII and $\mathrm{G} \gamma_{2}$-GFP10 (Table 1 and Fig. 1B). The same BRET-based cellular approach was used to monitor the activation of G $\alpha_{o A}$ by using the $\mathrm{G} \alpha_{\mathrm{oA}}$-RlucII and G $\gamma_{1}$-GFP10 constructs (Table 1 and Fig. 1C) or to measure the ability of (C) 2018. This manuscript version is made available under the CC-BY-NC-ND 4.0 license http://creativecommons.org/licenses/by-nc-nd/4.0/ 
This is the accepted (postprint) version of the following article: Besserer-Offroy É, et al. (2018), Pharmacol Res. doi: 10.1016/j.phrs.2018.02.032, which has been accepted and published in its final form at https://www.sciencedirect.com/science/article/pii/S1043661817313804

these apelin-13 analogs to recruit $\beta$-arrestins 1 and 2 ( $\beta$ arrs) to activated APJ-GFP10 receptor

(Table 1 and Fig. 1D, E). The use of cells endogenously expressing APJ would have been more relevant, however this was not technically feasible since we need to use the APJ-GFP10 recombinant construct to monitor the recruitment of the Rluc- $\beta$ arrs at APJ by BRET.

In the cellular functional assays, all compounds acted as full agonists in both the inhibition of cAMP production and $\mathrm{G \alpha}_{\mathrm{i} / \mathrm{o}}$ assays, as they triggered a maximal response $\left(\mathrm{E}_{\max }\right)$ comparable to apelin-13 (Supplementary Table S1). The potency $\left(\mathrm{EC}_{50}\right)$ of these analogs to inhibit the forskolin-induced cAMP production closely paralleled their binding affinities. Indeed, compounds 6 and 8 were extremely effective at inhibiting cAMP production, with a 20- to 30 -fold gain compared to apelin-13. In contrast, compound 7 was found to be more than 100 -fold less potent at inhibiting cAMP formation, when compared to apelin-13 (Table 1). BRET-based assays monitoring the engagement of $\mathrm{G} \alpha_{\mathrm{i} 1}$ and $\mathrm{G} \alpha_{\mathrm{oA}}$ revealed potencies in the same order of magnitude as for the reference ligand apelin-13 (Table 1). Consequently, we did not observe a direct correlation between cAMP inhibition and $\mathrm{G \alpha}_{\mathrm{i} / \mathrm{o}}$ activation. Compounds $\mathbf{6}$ and $\mathbf{8}$ displayed an increase in cAMP inhibition accompanied with no or very small changes in $G \alpha_{i 1}$ and $G \alpha_{0 A}$ activation. Likewise, compound 7 showed a 5-fold decrease in $\mathrm{G}_{\mathrm{il}}$ activation, no change in $\mathrm{G} \alpha_{\mathrm{oA}}$ activation while inhibiting cAMP production with 100-fold less potency. In explanation of these discrepancies between cAMP inhibition and G protein activation, it may be argued that C-terminal modified analogs recruit distinct $\mathrm{G} \alpha_{\mathrm{i} / \mathrm{o}}$ isoforms than $\mathrm{G} \alpha_{\mathrm{i} 1}$ and $\mathrm{G} \alpha_{\mathrm{oA}}$, such as $\mathrm{G} \alpha_{\mathrm{i} 2,3}$ or $\mathrm{G} \alpha_{\mathrm{oB}}$ to inhibit cAMP production [29]. This hypothesis is supported by the fact that the apelin fragments promote the coupling of APJ to either $\mathrm{G} \alpha_{\mathrm{i} 1}$ or $\mathrm{G} \alpha_{\mathrm{i} 2}$ but not to $\mathrm{G} \alpha_{\mathrm{i} 3}$ [30]. Differences between cAMP inhibition and $\mathrm{G} \alpha_{\mathrm{i} / \mathrm{o}}$ activation may also arise from activation specificities among the nine cloned

(C) 2018. This manuscript version is made available under the CC-BY-NC-ND 4.0 license http://creativecommons.org/licenses/by-nc-nd/4.0/ 
This is the accepted (postprint) version of the following article: Besserer-Offroy É, et al. (2018), Pharmacol Res. doi: 10.1016/j.phrs.2018.02.032, which has been accepted and published in its final form at https://www.sciencedirect.com/science/article/pii/S1043661817313804

isoforms of adenylyl cyclase (AC) [31]. Indeed, AC must be pre-stimulated, generally using forskolin to induce cAMP production in order to measure inhibition of the enzyme in a second step. Despite wide use in cell-based high-throughput screening assay, this approach is at risk of biased interpretations since forskolin preferentially activates $\mathrm{AC}_{\mathrm{I}}, \mathrm{AC}_{\mathrm{V}}$ or $\mathrm{AC}_{\mathrm{VI}}$ and may also bind different adenylyl cyclase regions than G-proteins thus inducing different conformations of the enzyme catalytic core [32-34].

To further investigate the signaling signature of these apelin-13 analogs, we studied Barr recruitment to APJ by measuring BRET signals of Rluc-ßarr 1 or 2 association to activated APJGFP10 receptor in living cells (Table 1 and Fig. 1D, E). Interestingly, the substitution of the Cterminal Phe ${ }^{13}$ residue of apelin-13 led to different classes of compounds displaying distinct $\beta$ arr recruitment profiles. Indeed, replacement of $\mathrm{Phe}^{13}$ by a lipophilic amino acid such as Val or Ala (compounds $\mathbf{2}$ and 10, respectively) decreased the recruitment of both $\beta$ arrs whereby compound 10 appeared to act as a partial agonist in this paradigm (Table 1 and Supplementary Table S1). Substitution of $\mathrm{Phe}^{13}$ with a residue having a shortened side chain residue (PheGly, compound 9) was also deleterious for recruiting $\beta$ arrs with a near 5-fold loss compared to the endogenous ligand, apelin-13. On the other hand, replacing $\mathrm{Phe}^{13}$ with $\mathrm{Phe}(4 \mathrm{Me})$, an electron donating residue (compound 3), or with amino acids having increased electron density and steric hindrance (such as $\operatorname{Tyr}(\mathrm{OBn})$ or Bpa, compounds $\mathbf{5}$ and $\mathbf{6}$, respectively), led to an improvement in $\beta$ arr 1 and $\beta$ arr 2 recruitment. These results indicate that two physical properties, length and steric hindrance of residue 13's side chain, play a critical role in recruiting ßarrs by APJ. We postulate that APJ's orthosteric sub-binding pocket accommodating apelin-13's C-terminal residue needs to be entirely filled to induce $\beta$ arr recruitment. It has been previously shown that this sub-pocket can

(c) 2018. This manuscript version is made available under the CC-BY-NC-ND 4.0 license http://creativecommons.org/licenses/by-nc-nd/4.0/ 
This is the accepted (postprint) version of the following article: Besserer-Offroy É, et al. (2018), Pharmacol Res. doi: 10.1016/j.phrs.2018.02.032, which has been accepted and published in its final form at $h t t p s: / / w w w . s c i e n c e d i r e c t . c o m / s c i e n c e / a r t i c l e / p i i / S 1043661817313804$

accommodate residues with large aromatic side chains but there is a limit of steric hindrance the pocket can tolerate [18]. Indeed, the substitution of $\mathrm{Phe}^{13}$ with dihydroanthranylAla residue (compound 7) had a deleterious effect on $\beta$ arr recruitment. In fact, this compound elicited a 5- and 12-fold loss of $\beta$ arr 1 and $\beta$ arr 2 recruitment when compared to apelin-13, respectively (Table 1). This negative effect of large side chain residues has been previously observed with a diphenylalanine substitution which led to a 7-fold decrease in $\beta$ arr 2 recruitment [18]. Furthermore, these findings are supported by the recent published X-ray crystallographic structure of APJ in complex with an apelin-17 derivative showing the shape of the C-terminal cavity delineated by side chains of Y35, W85, Y88, Y93 and Y299 [35]. Finally, the ( $L-\alpha-\mathrm{Me}) \mathrm{Phe}$ substitution (compound 8) was found to improve $\beta$ arr recruitment compared to apelin-13 (7- and 4-fold increase, respectively) which led to one of the most potent apelin-13 analog reported to date [19].

Altogether, these results revealed that modifications of the C-terminal $\mathrm{Phe}^{13}$ residue exert only small effects on the activation of $\mathrm{G}_{\mathrm{i} / \mathrm{o}}$. This is in accordance with previous findings demonstrating that the C-terminal end of apelin-13 and apelin-17 (Lys-Phe-Arg-Arg-apelin-13) does not play a major role in the inhibition of cAMP production [5,12,21]. In sharp contrast, the substitution of the $\mathrm{C}$-terminal $\mathrm{Phe}{ }^{13}$ residue significantly affects the ability of these modified analogs to recruit $\beta$ arrestins. Accordingly, deletion or replacement of the C-terminal residue in apelin-13 or apelin-17 by Ala also influences APJ receptor internalization [12,21,22]. In addition to these in vitro observations, the single C-terminal amino acid modification further abolishes the ability of these analogs to modulate blood pressure in vivo, thus demonstrating the importance of the role played by this residue in the APJ-triggered MABP lowering [12,36].

\subsection{Determination of the "within-pathway" relative efficacy of the analogs}

(C) 2018. This manuscript version is made available under the CC-BY-NC-ND 4.0 license http://creativecommons.org/licenses/by-nc-nd/4.0/ 
This is the accepted (postprint) version of the following article: Besserer-Offroy É, et al. (2018), Pharmacol Res. doi: 10.1016/j.phrs.2018.02.032, which has been accepted and published in its final form at $h t t p s: / / w w w . s c i e n c e d i r e c t . c o m / s c i e n c e / a r t i c l e / p i i / S 1043661817313804$

Characterization and quantification of the agonist's activity should be evaluated in a manner that allows the use of statistical methods to compare the differences in agonist activity of the tested analogs. Traditional methods, such as comparison of $\mathrm{pEC}_{50}$ or $\mathrm{E}_{\max }$ values, are inadequate due to system bias [37]. To properly quantify the agonistic properties of our analogs, we thus applied the Black and Leff operational model to assess the relative efficacy of our compounds compared to apelin-13 [28]. Considering affinity as well as agonist's efficacy, the Black and Leff [27] operational model specifically quantifies the transduction coefficient defined by $\log \left(\tau / \mathrm{K}_{\mathrm{A}}\right)$ which fully characterizes the selective activation of cellular signaling pathways by a given agonist. A comprehensive procedure of transduction coefficient quantification is detailed in the methods section and in the supporting information (Supplementary Note S1).

Using eq. (3), each concentration-response curve was fitted with the Black and Leff operational model describing receptor activation to derive the transduction coefficient, $\log \left(\tau / \mathrm{K}_{\mathrm{A}}\right)$, as a representation of the analog effect on receptor ability to trigger different signaling pathways (Supplementary Table S2). Since apelin-13 is the endogenous ligand of APJ, it was used as the reference ligand to which all other ligands were referred to in a "within-pathway" comparison using eq. (5), resulting in the $\Delta \log \left(\tau / \mathrm{K}_{\mathrm{A}}\right)$, the normalized transduction coefficient. The relative efficacy (RE) of the analogs for each pathway, relative to apelin-13, was determined by eq. (6). The normalized transduction coefficient $\left(\Delta \log \left(\tau / \mathrm{K}_{\mathrm{A}}\right)\right)$ and $\mathrm{RE}$ are reported in Table 2 . A graphical representation of the agonist activity of each analog for all the studied pathways is represented in Fig. 2. Compounds 2, 4, 7, 9, and 10 exhibited similar profiles and were generally less potent than the reference apelin-13 to trigger a cellular response. However, compounds $\mathbf{3}, \mathbf{5}, \mathbf{6}$, and $\mathbf{8}$ either

(C) 2018. This manuscript version is made available under the CC-BY-NC-ND 4.0 license http://creativecommons.org/licenses/by-nc-nd/4.0/ 
This is the accepted (postprint) version of the following article: Besserer-Offroy É, et al. (2018), Pharmacol Res. doi: 10.1016/j.phrs.2018.02.032, which has been accepted and published in its final form at https://www.sciencedirect.com/science/article/pii/S1043661817313804

showed similar or slightly improved profiles in terms of efficacy when compared to apelin-13. We then quantified the action of our compounds on the APJ-mediated hypotensive action.

\subsection{Hypotensive effect of apelin-13 and analogs}

We first determined the hypotensive action of different doses of the reference ligand apelin-13 by measuring the MABP, in response to a bolus injection, using a non-invasive tail-cuff system in anesthetized male rats. Apelin-13 triggered a rapid and transient MABP drop that returned to basal levels within 6 minutes following intravenous injection (Fig 3A). This hypotensive action of apelin-13 was found to be dose-dependent with a determined $\mathrm{ED}_{50}$ of $0.12 \pm 0.04 \mathrm{mg} / \mathrm{kg}$ (Fig. 3B). We further demonstrated that the hypotensive action of apelin-13 is dependent on the activation of the NO-dependent signaling pathway since L-NAME, a nitric oxide synthase inhibitor, totally abolished apelin-13-triggered MABP drop (Supplementary Fig. S1). The acute activation of the apelinergic system observed here is in accordance with previous findings showing that single intravenous injection of apelin-13 in Inactin-anesthetized male Wistar rats led to a rapid blood pressure lowering that last no more than 3-4 min [2,38-40]. Based on these results, it was argued in the literature that the APJ receptor might be a promising therapeutic target in the context of hypertension and pulmonary arterial hypertension $[41,42]$. Accordingly, the group of Davenport recently demonstrated that daily intraperitoneal injection of ELABELA, a second short-lived endogenous agonist peptide that binds APJ, significantly reduces the pathology of monocrotalineinduced rat model of pulmonary arterial hypertension [43]. Furthermore, acute apelin injection was previously reported to transiently reduce the MABP of spontaneously hypertensive rats almost as efficient as seen in Wistar-Kyoto control rats [44]. Altogether, these results suggest that 
This is the accepted (postprint) version of the following article: Besserer-Offroy É, et al. (2018), Pharmacol Res. doi: 10.1016/j.phrs.2018.02.032, which has been accepted and published in its final form at https://www.sciencedirect.com/science/article/pii/S1043661817313804

targeting the apelinergic system might indeed be therapeutically relevant in the context of hypertension.

In order to use a dose that would allow us to detect whether our analogs were more or less potent than apelin-13 to lower the MABP, we then monitored the hypotensive response induced by our compounds at a dose of $0.1 \mathrm{mg} / \mathrm{kg}$, which corresponded to the determined ED50 of apelin-13. The maximum drop of MABP measured after iv injection of our analogs is shown in Fig. 3C. Compounds 2, 3, 5 and $\mathbf{8}$ were found to reduce MABP, similarly to apelin-13. Compounds 4, $\mathbf{6}$, and 9 triggered an intermediate MABP drop between apelin-13 and saline injections. Furthermore, the $\triangle \mathrm{MABP}$ of those compounds were not significantly different from apelin-13 or saline injections. Finally, compounds $\mathbf{7}$ and $\mathbf{1 0}$ did not elicit reductions in blood pressure having similar profiles to saline (complete time courses of the blood pressure response for all the analogs are presented in Supplementary Fig. S2). These results allowed us to differentiate three classes of compounds: compounds that had similar properties to apelin-13, compounds exhibiting an intermediate profile and compounds that did not induce MABP lowering. We then attempted to see whether a comparable clustering of compounds existed within a particular APJ receptor signaling pathway, thereby correlating physiological effects and cell signaling. Previous results suggested that the MABP drop induced by apelin peptides is mediated by a $\mathrm{G}_{\mathrm{i} / \mathrm{o}}$-independent signaling pathway but potentially triggered by an internalization-related pathway $[12,19,22]$. We found that compounds with a MABP reducing behavior similar to apelin-13 usually had a $\beta$ arr recruitment RE equivalent to that of apelin-13, whereas the intermediate compounds possessed a ßarr recruitment RE between 1- and 5-fold less than apelin-13. Finally, compounds $\mathbf{7}$ and $\mathbf{1 0}$ were found to have a $\beta$ arr recruitment RE of 5- to 15-fold less than the reference. These results prompted

(C) 2018. This manuscript version is made available under the CC-BY-NC-ND 4.0 license http://creativecommons.org/licenses/by-nc-nd/4.0/ 
This is the accepted (postprint) version of the following article: Besserer-Offroy É, et al. (2018), Pharmacol Res. doi: 10.1016/j.phrs.2018.02.032, which has been accepted and published in its final form at https://www.sciencedirect.com/science/article/pii/S1043661817313804

us to link $\beta$ arr recruitment to the hypotensive effect of the compounds. We first assessed whether the normalized transduction coefficients found for all analogs were significantly different from the one of apelin-13 for each of the studied signaling pathways in a Kruskal-Wallis followed by a Dunn's post hoc test (Supplementary Table S3). To confirm our hypothesis and since at least one analog possessed a normalized transduction coefficient significantly different from apelin-13 in each signaling assay, we performed different correlations between the $\triangle \mathrm{MABP}$ and the $\Delta \log (\tau / \mathrm{KA})$ for each studied pathway (Fig. 4 and Supplementary Fig. S3). Only the two correlations with the $\Delta \log (\tau / \mathrm{KA})$ for $\beta$ arr recruitment were found to be statistically significant, whereas no correlations were found between $\Delta \mathrm{MABP}$ and the $\Delta \log (\tau / \mathrm{KA})$ for the $\mathrm{G} \alpha_{\mathrm{i} / \mathrm{o}}-\mathrm{related}$ pathways (i.e. cAMP inhibition, $\mathrm{G} \alpha_{\mathrm{i}}$, and $\mathrm{G} \alpha_{\mathrm{oA}}$ ). Spearman correlation of $\triangle \mathrm{MABP}$ and $\Delta \log (\tau / \mathrm{KA})_{\beta \text {-arrestin } 1}$ was found to be statistically significant with a $p$ value of 0.0022 and a $\mathrm{r}$ of

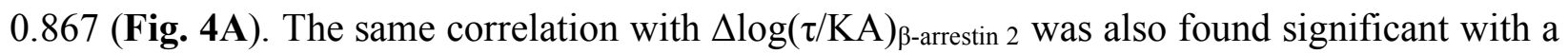
$p$ value of 0.0016 and a $r$ of 0.879 (Fig. 4B).

In the present study, we thus demonstrate the key role played by the C-terminal residue of apelin13 for the modulation of $\beta$ arr recruitment to APJ and the involvement of this signaling pathway in the hypotensive response mediated through APJ. We also found that modulation of the $\beta$ arr recruitment by substituting $\mathrm{Ph}^{13}$ with natural and unnatural amino acids led to the modulation of the blood pressure lowering effect. This is also confirmed by a recent study aimed at developing apelin-13 macrocyclic analogs where three compounds (compounds 7, 15 and 20; structures of these compounds can be found in Supplementary Scheme S1, upper panel) were shown to induce a hypotensive effect significantly different from the one mediated by apelin-13 at an equimolar dose [45]. When looking at the activation profile of those analogs, we further observed that those

(C) 2018. This manuscript version is made available under the CC-BY-NC-ND 4.0 license http://creativecommons.org/licenses/by-nc-nd/4.0/ 
This is the accepted (postprint) version of the following article: Besserer-Offroy É, et al. (2018), Pharmacol Res. doi: 10.1016/j.phrs.2018.02.032, which has been accepted and published in its final form at https://www.sciencedirect.com/science/article/pii/S1043661817313804

three compounds had a decreased ability to induce $\beta$ arr recruitment compared to apelin- 13 while they conserved their capacity to bind to APJ and to activate $\mathrm{G} \alpha_{i 1}$ and $\mathrm{G} \alpha_{\mathrm{oA}}$ pathways. Likewise, the cyclic apelin peptide MM07, which preferentially activates G-protein coupling over ßarr signaling was reported to be not effective in lowering MABP [46].

Furthermore, this structure-activity relationship (SAR) was also true when assessing the second endogenous ligand of APJ, ELABELA/Toddler. Indeed, the discovery and SAR of the minimally bioactive fragment of ELABELA/Toddler revealed two compounds (compounds 3 and 4; see compound's structures in Supplementary Scheme S1, lower panel) that displayed biased profiling comparable to the one observed for the macrocyclic compounds [47]. Those two compounds exhibited lower efficacies at recruiting $\beta$ arr 2 and lower reduction of MABP. Altogether, our results, as well as previously published findings indicate that $\beta$ arr recruitment at the APJ receptor represents the initiating signaling step that regulates the hypotensive action mediated by apelin peptides. Interestingly, ELA(19-32), compound 3, still triggers an increased left ventricular developed pressure (LVDP) in the same range of apelin-13 while its potency to mediate a hypotensive response is decreased. This suggests that the inotropic effect of APJ is mediated through a signaling pathway distinct from $\beta$ arr recruitment [8].

It has already been proposed that $\beta$ arr recruitment plays an important role in blood vessel relaxation. Indeed, apelin-17 was shown to counteract angiotensin II mediated glomerular arteriole constriction while apelin-17 lacking the C-terminus amino acid (K16P) had no effect on arteriole diameter [22]. The authors thus concluded that apelin-17 caused a decrease in MABP through a ßarr-dependent ERK1/2 activation process. Following binding to APJ, apelin-13 has, however, been shown to provoke PTX-sensitive ERK1/2 phosphorylation via a PKC-dependent mechanism

(C) 2018. This manuscript version is made available under the CC-BY-NC-ND 4.0 license http://creativecommons.org/licenses/by-nc-nd/4.0/ 
This is the accepted (postprint) version of the following article: Besserer-Offroy É, et al. (2018), Pharmacol Res. doi: 10.1016/j.phrs.2018.02.032, which has been accepted and published in its final form at https://www.sciencedirect.com/science/article/pii/S1043661817313804

in a Ras-independent manner [17]. It is therefore unlikely here that the hypotensive action of apelin-13, mediated via the $\beta$ arr-dependent pathway, relies on the activation of the ERK1/2 signaling cascade. This is not the first time that the binding of different apelin fragments (i.e. apelin-13, -17 or -36) to the APJ receptor behaves differently. Lee et al., have previously reported that apelin-13 induces a rapid recycling of the receptor to the cell surface after internalization via a Rab4-dependent process, whereas apelin-36 internalized receptors remain associated with Barrestins and are targeted to the lysosomal compartment by Rab7 [20]. Likewise, it was also demonstrated that short and long forms of apelin exhibit distinct desensitization profiles. Indeed, the deletion of the C-terminal tail of APJ decreases the desensitization pattern induced by apelin36 without altering the desensitization profile related to APJ activation by apelin-13 [30].

The hypotensive action of apelin has been shown to be mediated through a NO-dependent mechanism since L-NAME blocked the apelin-mediated MABP lowering. [12,48]. Therefore, the link between $\beta$ arr recruitment and NO production needs to be addressed. The serine/threonine kinase, Akt, has been shown to be activated by several proteins such as PI3K and $\beta$ arrs [49-51] and has also been linked to the activation of the endothelial isoform of NO-synthase [52]. We can therefore hypothesize that activation of Akt could stimulate NO production in endothelial cells by a ßarr-dependent mechanism. This is of particular interest since apelin, following binding on APJ, was shown to induce the phosphorylation of Akt in endothelial cells [53,54]. Furthermore, mechanical stretch has been recently reported to activate APJ in a biased manner by favoring ßarr over $\mathrm{G} \alpha_{\mathrm{i} / \mathrm{o}}$ signaling $[55,10]$. Thus, this mechanism could play a protective role by inducing a hypotensive response, hence decreasing mechanical stretch.

(c) 2018. This manuscript version is made available under the CC-BY-NC-ND 4.0 license http://creativecommons.org/licenses/by-nc-nd/4.0/ 
This is the accepted (postprint) version of the following article: Besserer-Offroy É, et al. (2018), Pharmacol Res. doi: 10.1016/j.phrs.2018.02.032, which has been accepted and published in its final form at https://www.sciencedirect.com/science/article/pii/S1043661817313804

(C) 2018. This manuscript version is made available under the CC-BY-NC-ND 4.0 license http://creativecommons.org/licenses/by-nc-nd/4.0/ 


\section{Conclusion}

We have demonstrated that the hypotensive effect mediated by APJ is significantly correlated with the recruitment of $\beta$ arrs. Furthermore, we identified that the recruitment of $\beta$ arr can be modulated by modifying the C-terminal residue of apelin-13 and that potent agonists at stimulating $\beta$ arr translocation were effective in lowering MABP. We bring new insight into APJ-mediated signaling and the relationship that exists between the physiological action of a hormone and its downstream signaling pathways. Further studies are, however, required to discriminate which signaling pathway, acting downstream of $\beta$ arr activation, is involved in the hypotensive action mediated by apelin binding to APJ. Finally, the development of biased apelin receptor agonists will be of great interest to decipher the physiopathological roles played by the apelinergic axis and to potentially offer new and effective treatment options for cardiovascular disease.

\section{Supplementary material}

Fitting parameters and equations to retrieve ligand-specific parameters of receptor activation using GraphPad Prism, structure of cited macrocyclic analogs of apelin-13 and ELABELA analogs, effect of L-NAME on apelin-13-mediated hypotensive response, time-course of the hypotensive response triggered by the apelin analogs, correlations between $\Delta \mathrm{MABP}$ and the $\Delta \log (\tau / \mathrm{KA})$ for the $\mathrm{G \alpha}_{\mathrm{i} / \mathrm{o}}$-related pathways, Emax table, $\log (\tau / \mathrm{KA})$ table, and statistical analysis of $\Delta \log (\tau / \mathrm{KA})$ table are available as supplementary information PDF file. 
This is the accepted (postprint) version of the following article: Besserer-Offroy É, et al. (2018), Pharmacol Res. doi: 10.1016/j.phrs.2018.02.032, which has been accepted and published in its final form at https://www.sciencedirect.com/science/article/pii/S1043661817313804

\section{Acknowledgments}

ÉBO was supported by a research fellowship from the Institut de pharmacologie de Sherbrooke (IPS) and Centre d'excellence en neurosciences de l'Université de Sherbrooke (CNS). PS holds a Canada Research Chair in Neurophysiopharmacology of Chronic Pain. Drs M. Bouvier, T. Hebert, S.A. Laporte, G. Pineyro, J.-C. Tardif and E. Thorin (CQDM Team) are also acknowledged for providing us with the G-protein BRET-based biosensors.

\section{Funding}

This work was supported by the Canadian Institute of Health Research (CIHR) [grant number FDN-148413] to PS, the National Science and Engineering Research Council of Canada (NSERC) [grant number CRD-399680] to ÉM, and the FRQ-S funded Réseau québécois de recherche sur le médicament (RQRM). The authors declare no competing financial interests.

\section{Authors contribution}

Conception and design of study: ÉBO, ÉM, and PS

Acquisition of data: ÉBO, JML, PB, and JC

Analysis and interpretation of data: ÉBO, JML, ÉM, and PS

Contributed new reagent and analysis tools: ÉBO, AM, and ÉM

Wrote the manuscript: ÉBO, RD, OL, MAM, RL, JML, ÉM, and PS

All the authors approved the version of the manuscript to be published.

(C) 2018. This manuscript version is made available under the CC-BY-NC-ND 4.0 license http://creativecommons.org/licenses/by-nc-nd/4.0/ 
This is the accepted (postprint) version of the following article: Besserer-Offroy É, et al. (2018), Pharmacol Res. doi: 10.1016/j.phrs.2018.02.032, which has been accepted and published in its final form at https://www.sciencedirect.com/science/article/pii/S1043661817313804

\section{References}

[1] B.F. O'Dowd, M. Heiber, A. Chan, H.H. Heng, L.C. Tsui, J.L. Kennedy, et al., A human gene that shows identity with the gene encoding the angiotensin receptor is located on chromosome 11, Gene. 136 (1993) 355-360.

[2] D.K. Lee, R. Cheng, T. Nguyen, T. Fan, A.P. Kariyawasam, Y. Liu, et al., Characterization of apelin, the ligand for the APJ receptor, J Neurochem. 74 (2000) 3441.

[3] S.C. Chng, L. Ho, J. Tian, B. Reversade, ELABELA: A Hormone Essential for Heart Development Signals via the Apelin Receptor, Dev. Cell. 27 (2013) 672-680. doi:10.1016/j.devcel.2013.11.002.

[4] A.-M. O'Carroll, S.J. Lolait, L.E. Harris, G.R. Pope, The apelin receptor APJ: journey from an orphan to a multifaceted regulator of homeostasis, J. Endocrinol. 219 (2013) R13-35. doi:10.1530/JOE-13-0227.

[5] A.D. Medhurst, C.A. Jennings, M.J. Robbins, R.P. Davis, C. Ellis, K.Y. Winborn, et al., Pharmacological and immunohistochemical characterization of the APJ receptor and its endogenous ligand apelin, J Neurochem. 84 (2003) 1162-1172. doi:10.1046/j.14714159.2003.01587.x.

[6] A.M. O'Carroll, T.L. Selby, M. Palkovits, S.J. Lolait, Distribution of mRNA encoding B78/apj, the rat homologue of the human APJ receptor, and its endogenous ligand apelin in brain and peripheral tissues, Biochim. Biophys. Acta. 1492 (2000) 72-80.

(C) 2018. This manuscript version is made available under the CC-BY-NC-ND 4.0 license http://creativecommons.org/licenses/by-nc-nd/4.0/ 
[7] A.G. Japp, D.E. Newby, The apelin-APJ system in heart failure: pathophysiologic relevance and therapeutic potential, Biochem. Pharmacol. 75 (2008) 1882-1892. doi:10.1016/j.bcp.2007.12.015.

[8] I. Szokodi, P. Tavi, G. Földes, S. Voutilainen-Myllylä, M. Ilves, H. Tokola, et al., Apelin, the novel endogenous ligand of the orphan receptor APJ, regulates cardiac contractility, Circulation Research. 91 (2002) 434-440.

[9] M.J. Kleinz, J.N. Skepper, A.P. Davenport, Immunocytochemical localisation of the apelin receptor, APJ, to human cardiomyocytes, vascular smooth muscle and endothelial cells, Regul. Pept. 126 (2005) 233-240. doi:10.1016/j.regpep.2004.10.019.

[10] P. Yang, J.J. Maguire, A.P. Davenport, Apelin, Elabela/Toddler, and biased agonists as novel therapeutic agents in the cardiovascular system, Trends in Pharmacological Sciences. 36 (2015) 560-567. doi:10.1016/j.tips.2015.06.002.

[11] L. Lu, D. Wu, L. Li, L. Chen, Apelin/APJ system: A bifunctional target for cardiac hypertrophy, Int. J. Cardiol. 230 (2017) 164-170. doi:10.1016/j.ijcard.2016.11.215.

[12] S. El Messari, X. Iturrioz, C. Fassot, N. De Mota, D. Roesch, C. Llorens-Cortès, Functional dissociation of apelin receptor signaling and endocytosis: implications for the effects of apelin on arterial blood pressure, J Neurochem. 90 (2004) 1290-1301. doi:10.1111/j.1471-4159.2004.02591.x.

[13] A.G. Japp, N.L. Cruden, D.A.B. Amer, V.K.Y. Li, E.B. Goudie, N.R. Johnston, et al., Vascular effects of apelin in vivo in man, J. Am. Coll. Cardiol. 52 (2008) 908-913. doi:10.1016/j.jacc.2008.06.013.

[14] A.G. Japp, N.L. Cruden, G. Barnes, N. van Gemeren, J. Mathews, J. Adamson, et al., Acute cardiovascular effects of apelin in humans: potential role in patients with chronic (C) 2018. This manuscript version is made available under the CC-BY-NC-ND 4.0 license http://creativecommons.org/licenses/by-nc-nd/4.0/ 
This is the accepted (postprint) version of the following article: Besserer-Offroy É, et al. (2018), Pharmacol Res. doi: 10.1016/j.phrs.2018.02.032, which has been accepted and published in its final form at https://www.sciencedirect.com/science/article/pii/S1043661817313804

heart failure, Circulation. 121 (2010) 1818-1827.

doi:10.1161/CIRCULATIONAHA.109.911339.

[15] G. Földes, F. Horkay, I. Szokodi, O. Vuolteenaho, M. Ilves, K.A. Lindstedt, et al., Circulating and cardiac levels of apelin, the novel ligand of the orphan receptor APJ, in patients with heart failure, Biochemical and Biophysical Research Communications. 308 (2003) 480-485. doi:10.1016/S0006-291X(03)01424-4.

[16] K.S. Chong, R.S. Gardner, J.J. Morton, E.A. Ashley, T.A. McDonagh, Plasma concentrations of the novel peptide apelin are decreased in patients with chronic heart failure, European Journal of Heart Failure. 8 (2006) 355-360.

doi:10.1016/j.ejheart.2005.10.007.

[17] B. Masri, H. Lahlou, H. Mazarguil, B. Knibiehler, Y. Audigier, Apelin (65-77) activates extracellular signal-regulated kinases via a PTX-sensitive G protein, Biochemical and Biophysical Research Communications. 290 (2002) 539-545. doi:10.1006/bbrc.2001.6230.

[18] A. Murza, A. Parent, É. Besserer-Offroy, H. Tremblay, F. Karadereye, N. Beaudet, et al., Elucidation of the structure-activity relationships of apelin: influence of unnatural amino acids on binding, signaling, and plasma stability, ChemMedChem. 7 (2012) 318 325. doi:10.1002/cmdc.201100492.

[19] A. Murza, É. Besserer-Offroy, J. Côté, P. Bérubé, J.-M. Longpré, R. Dumaine, et al., CTerminal modifications of apelin-13 significantly change ligand binding, receptor signaling, and hypotensive action, J. Med. Chem. 58 (2015) 2431-2440. doi:10.1021/jm501916k.

(c) 2018. This manuscript version is made available under the CC-BY-NC-ND 4.0 license http://creativecommons.org/licenses/by-nc-nd/4.0/ 
[20] D.K. Lee, S.S.G. Ferguson, S.R. George, B.F. O’Dowd, The fate of the internalized apelin receptor is determined by different isoforms of apelin mediating differential interaction with beta-arrestin, Biochemical and Biophysical Research Communications. 395 (2010) 185-189. doi:10.1016/j.bbrc.2010.03.151.

[21] X. Iturrioz, R. Gerbier, V. Leroux, R. Alvear-Perez, B. Maigret, C. Llorens-Cortès, By interacting with the C-terminal Phe of apelin, Phe255 and Trp259 in helix VI of the apelin receptor are critical for internalization, Journal of Biological Chemistry. 285 (2010) 32627-32637. doi:10.1074/jbc.M110.127167.

[22] E. Ceraudo, C. Galanth, E. Carpentier, I. Banegas-Font, A.-M. Schonegge, R. AlvearPerez, et al., Biased signaling favoring gi over $\beta$-arrestin promoted by an apelin fragment lacking the C-terminal phenylalanine, Journal of Biological Chemistry. 289 (2014) 24599-24610. doi:10.1074/jbc.M113.541698.

[23] F.F. Hamdan, M. Audet, P. Garneau, J. Pelletier, M. Bouvier, High-throughput screening of $\mathrm{G}$ protein-coupled receptor antagonists using a bioluminescence resonance energy transfer 1-based beta-arrestin2 recruitment assay, Journal of Biomolecular Screening. 10 (2005) 463-475. doi:10.1177/1087057105275344.

[24] M. Richard-Lalonde, K. Nagi, N. Audet, R. Sleno, M. Amraei, M. Hogue, et al., Conformational dynamics of Kir3.1/Kir3.2 channel activation via $\delta$-opioid receptors, Molecular Pharmacology. 83 (2013) 416-428. doi:10.1124/mol.112.081950.

[25] C. Galés, J.J.J. Van Durm, S. Schaak, S. Pontier, Y. Percherancier, M. Audet, et al., Probing the activation-promoted structural rearrangements in preassembled receptor-G protein complexes, Nat. Struct. Mol. Biol. 13 (2006) 778-786. doi:10.1038/nsmb1134. 
[26] C. Ehrhardt, M. Schmolke, A. Matzke, A. Knoblauch, C. Will, V. Wixler, et al., Polyethylenimine, a cost-effective transfection reagent, Signal Transduction. 6 (2006) 179-184. doi:10.1002/sita.200500073.

[27] J.W. Black, P. Leff, Operational models of pharmacological agonism, Proc. R. Soc. Lond., B, Biol. Sci. 220 (1983) 141-162.

[28] T.P. Kenakin, C. Watson, V. Muniz-Medina, A. Christopoulos, S. Novick, A simple method for quantifying functional selectivity and agonist bias, ACS Chem Neurosci. 3 (2012) 193-203. doi:10.1021/cn200111m.

[29] J. Bockaert, Molecular tinkering of G protein-coupled receptors: an evolutionary success, The EMBO Journal. 18 (1999) 1723-1729. doi:10.1093/emboj/18.7.1723.

[30] B. Masri, N. Morin, L. Pedebernade, B. Knibiehler, Y. Audigier, The apelin receptor is coupled to Gi1 or Gi2 protein and is differentially desensitized by apelin fragments, J. Biol. Chem. 281 (2006) 18317-18326. doi:10.1074/jbc.M600606200.

[31] R. Sadana, C.W. Dessauer, Physiological roles for G protein-regulated adenylyl cyclase isoforms: insights from knockout and overexpression studies, Neurosignals. 17 (2009) 5-22. doi:10.1159/000166277.

[32] E.M. Sutkowski, W.J. Tang, C.W. Broome, J.D. Robbins, K.B. Seamon, Regulation of forskolin interactions with type I, II, V, and VI adenylyl cyclases by Gs alpha, Biochemistry. 33 (1994) 12852-12859.

[33] M.H. Ghahremani, P. Cheng, P.M. Lembo, P.R. Albert, Distinct roles for Galphai2, Galphai3, and Gbeta gamma in modulation offorskolin- or Gs-mediated cAMP accumulation and calcium mobilization by dopamine D2S receptors, J. Biol. Chem. 274 (1999) 9238-9245. 
[34] J.J. Tesmer, R.K. Sunahara, A.G. Gilman, S.R. Sprang, Crystal structure of the catalytic domains of adenylyl cyclase in a complex with Gsalpha.GTPgammaS, Science. 278 (1997) 1907-1916.

[35] Y. Ma, Y. Yue, Y. Ma, Q. Zhang, Q. Zhou, Y. Song, et al., Structural Basis for Apelin Control of the Human Apelin Receptor, Structure. 25 (2017) 858-866.e4. doi:10.1016/j.str.2017.04.008.

[36] D.K. Lee, V.R. Saldivia, T. Nguyen, R. Cheng, S.R. George, B.F. O’Dowd, Modification of the terminal residue of apelin-13 antagonizes its hypotensive action, Endocrinology. 146 (2005) 231-236. doi:10.1210/en.2004-0359.

[37] T.P. Kenakin, A. Christopoulos, A. Christopoulos, Measurements of ligand bias and functional affinity, Nat Rev Drug Discov. 12 (2013) 483-483. doi:10.1038/nrd3954-c2.

[38] A. Reaux, N. De Mota, I. Skultetyova, Z. Lenkei, S. El Messari, K. Gallatz, et al., Physiological role of a novel neuropeptide, apelin, and its receptor in the rat brain, $\mathrm{J}$ Neurochem. 77 (2001) 1085-1096.

[39] K. Tatemoto, K. Takayama, M.X. Zou, I. Kumaki, W. Zhang, K. Kumano, et al., The novel peptide apelin lowers blood pressure via a nitric oxide-dependent mechanism, Regul. Pept. 99 (2001) 87-92.

[40] X. Cheng, X.S. Cheng, C.C.Y. Pang, Venous dilator effect of apelin, an endogenous peptide ligand for the orphan APJ receptor, in conscious rats, Eur. J. Pharmacol. 470 (2003) 171-175.

[41] J. Cao, H. Li, L. Chen, Targeting drugs to APJ receptor: the prospect of treatment of hypertension and other cardiovascular diseases, Cdt. 16 (2015) 148-155. 
[42] J. Kim, Apelin-APJ signaling: a potential therapeutic target for pulmonary arterial hypertension, Mol. Cells. 37 (2014) 196-201. doi:10.14348/molcells.2014.2308.

[43] P. Yang, C. Read, R.E. Kuc, G. Buonincontri, M. Southwood, R. Torella, et al., Elabela/Toddler Is an Endogenous Agonist of the Apelin APJ Receptor in the Adult Cardiovascular System, and Exogenous Administration of the Peptide Compensates for the Downregulation of Its Expression in Pulmonary Arterial Hypertension, Circulation. 135 (2017) 1160-1173. doi:10.1161/CIRCULATIONAHA.116.023218.

[44] J. Ishida, T. Hashimoto, Y. Hashimoto, S. Nishiwaki, T. Iguchi, S. Harada, et al., Regulatory roles for APJ, a seven-transmembrane receptor related to angiotensin-type 1 receptor in blood pressure in vivo, J. Biol. Chem. 279 (2004) 26274-26279. doi:10.1074/jbc.M404149200.

[45] A. Murza, X. Sainsily, J. Côté, L. Bruneau-Cossette, É. Besserer-Offroy, J.-M. Longpré, et al., Structure-activity relationship of novel macrocyclic biased apelin receptor agonists, Org. Biomol. Chem. 15 (2017) 449-458. doi:10.1039/c6ob02247b.

[46] A.L. Brame, J.J. Maguire, P. Yang, A. Dyson, R. Torella, J. Cheriyan, et al., Design, characterization, and first-in-human study of the vascular actions of a novel biased apelin receptor agonist, Hypertension. 65 (2015) 834-840.

doi:10.1161/HYPERTENSIONAHA.114.05099.

[47] A. Murza, X. Sainsily, D. Coquerel, J. Côté, P. Marx, É. Besserer-Offroy, et al., Discovery and Structure-Activity Relationship of a Bioactive Fragment of ELABELA that Modulates Vascular and Cardiac Functions, J. Med. Chem. 59 (2016) 2962-2972. doi:10.1021/acs.jmedchem.5b01549. 
This is the accepted (postprint) version of the following article: Besserer-Offroy É, et al. (2018), Pharmacol Res. doi: 10.1016/j.phrs.2018.02.032, which has been accepted and published in its final form at https://www.sciencedirect.com/science/article/pii/S1043661817313804

[48] K. Tatemoto, M. Hosoya, Y. Habata, R. Fujii, T. Kakegawa, M.X. Zou, et al., Isolation and characterization of a novel endogenous peptide ligand for the human APJ receptor, Biochemical and Biophysical Research Communications. 251 (1998) 471-476. doi:10.1006/bbrc.1998.9489.

[49] R. Goel, P.J. Phillips-Mason, D.M. Raben, J.J. Baldassare, alpha-Thrombin induces rapid and sustained Akt phosphorylation by beta-arrestin1-dependent and -independent mechanisms, and only the sustained Akt phosphorylation is essential for G1 phase progression, J. Biol. Chem. 277 (2002) 18640-18648. doi:10.1074/jbc.M108995200.

[50] T.J. Povsic, T.A. Kohout, R.J. Lefkowitz, Beta-arrestin1 mediates insulin-like growth factor 1 (IGF-1) activation of phosphatidylinositol 3-kinase (PI3K) and anti-apoptosis, J. Biol. Chem. 278 (2003) 51334-51339. doi:10.1074/jbc.M309968200.

[51] J.-M. Beaulieu, T.D. Sotnikova, S. Marion, R.J. Lefkowitz, R.R. Gainetdinov, M.G. Caron, An Akt/ $\beta$-Arrestin 2/PP2A Signaling Complex Mediates Dopaminergic Neurotransmission and Behavior, Cell. 122 (2005) 261-273.

[52] D. Fulton, J.P. Gratton, T.J. McCabe, J. Fontana, Y. Fujio, K. Walsh, et al., Regulation of endothelium-derived nitric oxide production by the protein kinase Akt, Nature. 399 (1999) 597-601. doi:10.1038/21218.

[53] J. Hamada, J. Kimura, J. Ishida, T. Kohda, S. Morishita, S. Ichihara, et al., Evaluation of novel cyclic analogues of apelin, Int. J. Mol. Med. 22 (2008) 547-552.

[54] R. Busch, A. Strohbach, M. Pennewitz, F. Lorenz, M. Bahls, M.C. Busch, et al., Regulation of the endothelial apelin/APJ system by hemodynamic fluid flow, Cell. Signal. 27 (2015) 1286-1296. doi:10.1016/j.cellsig.2015.03.011.

(c) 2018. This manuscript version is made available under the license http://creativecommons.org/licenses/by-nc-nd/4.0/ 
This is the accepted (postprint) version of the following article: Besserer-Offroy É, et al. (2018), Pharmacol Res. doi: 10.1016/j.phrs.2018.02.032, which has been accepted and published in its final form at https://www.sciencedirect.com/science/article/pii/S1043661817313804

[55] M.C. Scimia, C. Hurtado, S. Ray, S. Metzler, K. Wei, J. Wang, et al., APJ acts as a dual receptor in cardiac hypertrophy, Nature. 488 (2012) 394-398. doi:10.1038/nature11263. 
This is the accepted (postprint) version of the following article: Besserer-Offroy É, et al. (2018), Pharmacol Res. doi: 10.1016/j.phrs.2018.02.032, which has been accepted and published in its final form at $h t t p s: / / w w w . s c i e n c e d i r e c t . c o m / s c i e n c e / a r t i c l e / p i i / S 1043661817313804$

\section{Schemes, Figures, and Tables}

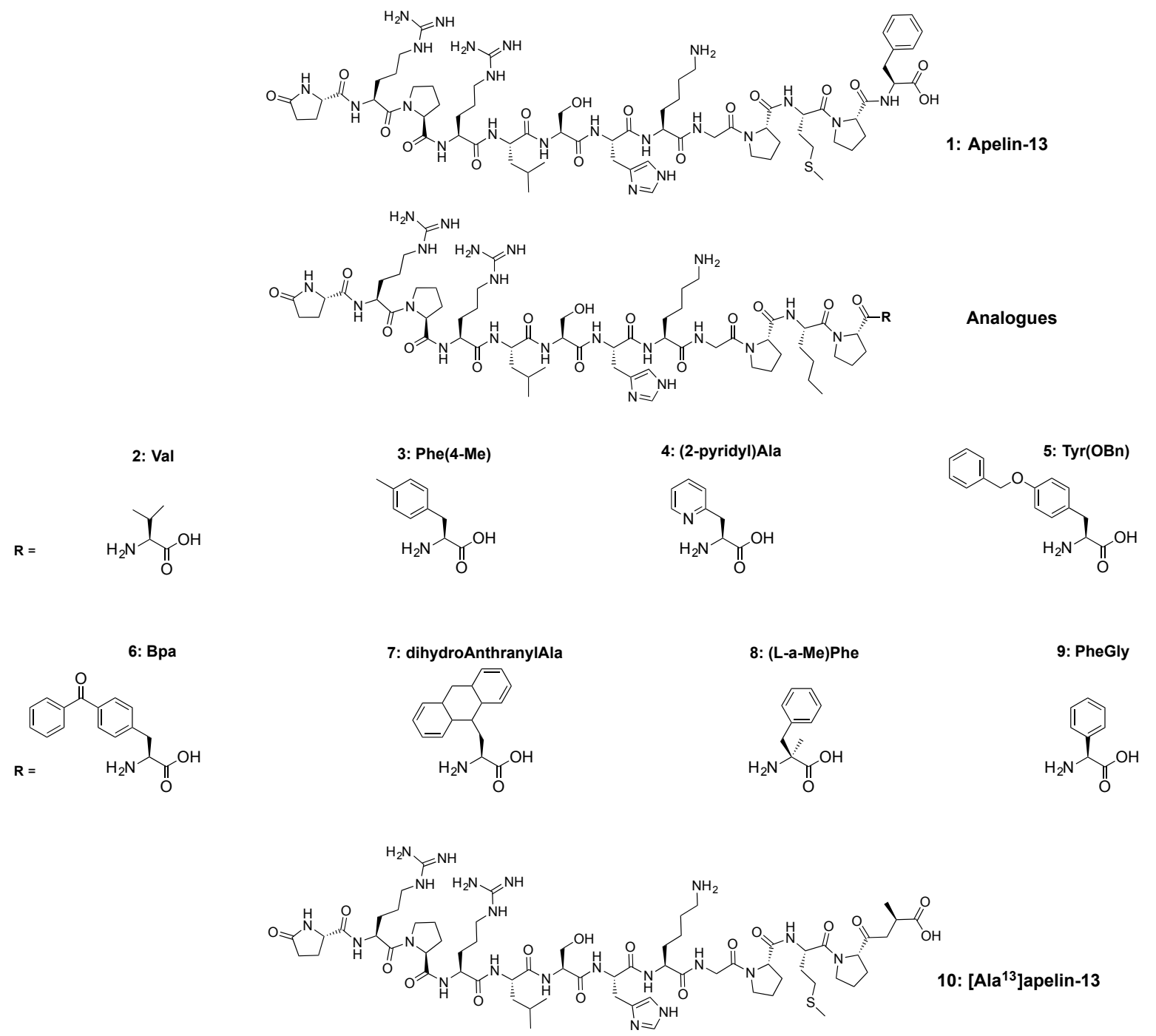

Scheme 1. Developed structures of apelin-13 and analogs used in this study.

(c) 2018. This manuscript version is made available under the CC-BY-NC-ND 
This is the accepted (postprint) version of the following article: Besserer-Offroy É, et al. (2018), Pharmacol Res. doi: 10.1016/j.phrs.2018.02.032, which has been accepted and published in its final form at https://www.sciencedirect.com/science/article/pii/S1043661817313804
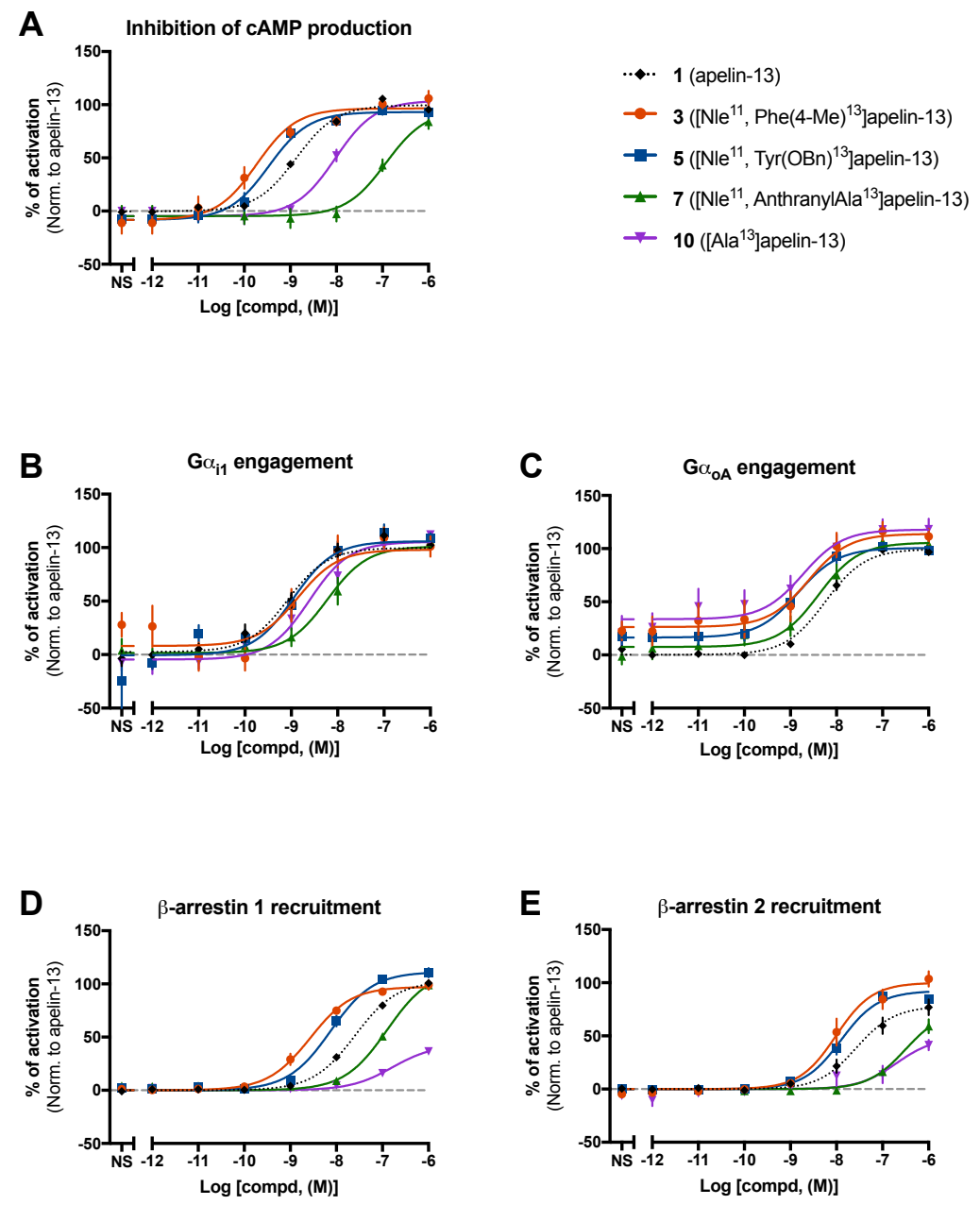

Fig. 1. Activation of signaling pathways triggered by apelin-13 and four representative Cterminally modified analogs. (A) Ligand-mediated inhibition of the forskolin-stimulated accumulation of cAMP measured using PerkinElmer's Lance Ultra cAMP assay. (B-C) Ligandtriggered engagement of the $G$ protein pathways $G \alpha_{i 1}(\mathbf{B})$ and $G \alpha_{o A}(\mathbf{C})$ monitored using the BRET-based G protein dissociation assay. (D-E) Ligand-induced recruitment of $\beta$ arr 1 (D) and Barr 2 (E) using the BRET-based $\beta$ arr recruitment assay. Each data set represents the mean of three independent experiments, each performed in triplicate, and expressed as the mean \pm S.E.M.

(c) 2018. This manuscript version is made available under the license http://creativecommons.org/licenses/by-nc-nd/4.0/ 
This is the accepted (postprint) version of the following article: Besserer-Offroy É, et al. (2018), Pharmacol Res. doi: 10.1016/j.phrs.2018.02.032, which has been accepted and published in its final form at $h t$ ttps://www.sciencedirect.com/science/article/pii/S1043661817313804
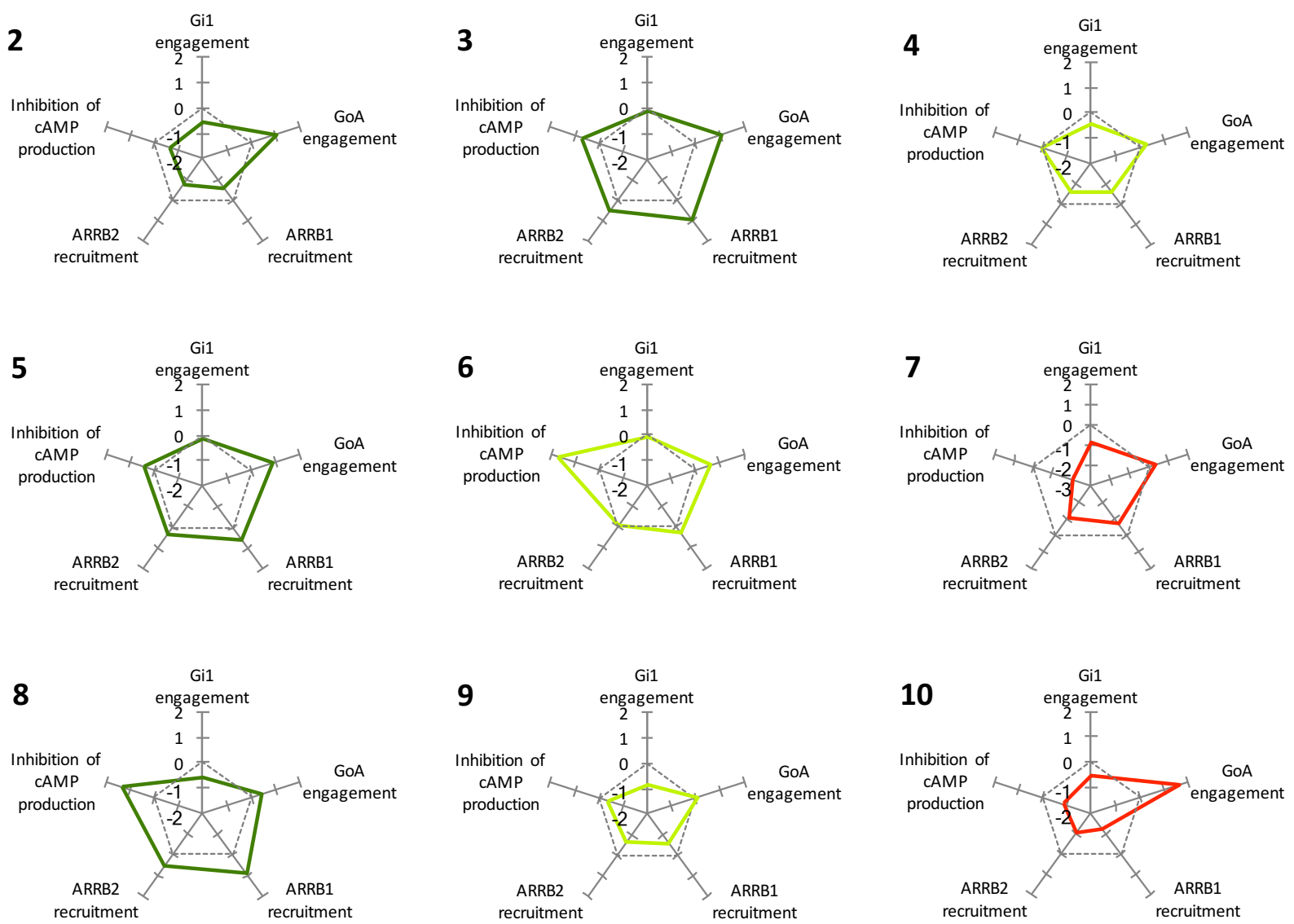

Fig. 2. Relative efficacy plots for each analog. The normalized transduction coefficient $\left(\Delta \log \left(\tau / \mathrm{K}_{\mathrm{A}}\right)\right)$, as calculated using the Black and Leff operational model, was graphed for each studied signaling pathway. Values for each analog are represented by the solid colored line and apelin-13's values are represented on each graph by the gray dashed line. Each point on graphs represents the mean $\Delta \log \left(\tau / \mathrm{K}_{\mathrm{A}}\right)$ of the analog for the specified signaling pathway and was calculated using concentration-response curves, which were the result of three independent experiments. 

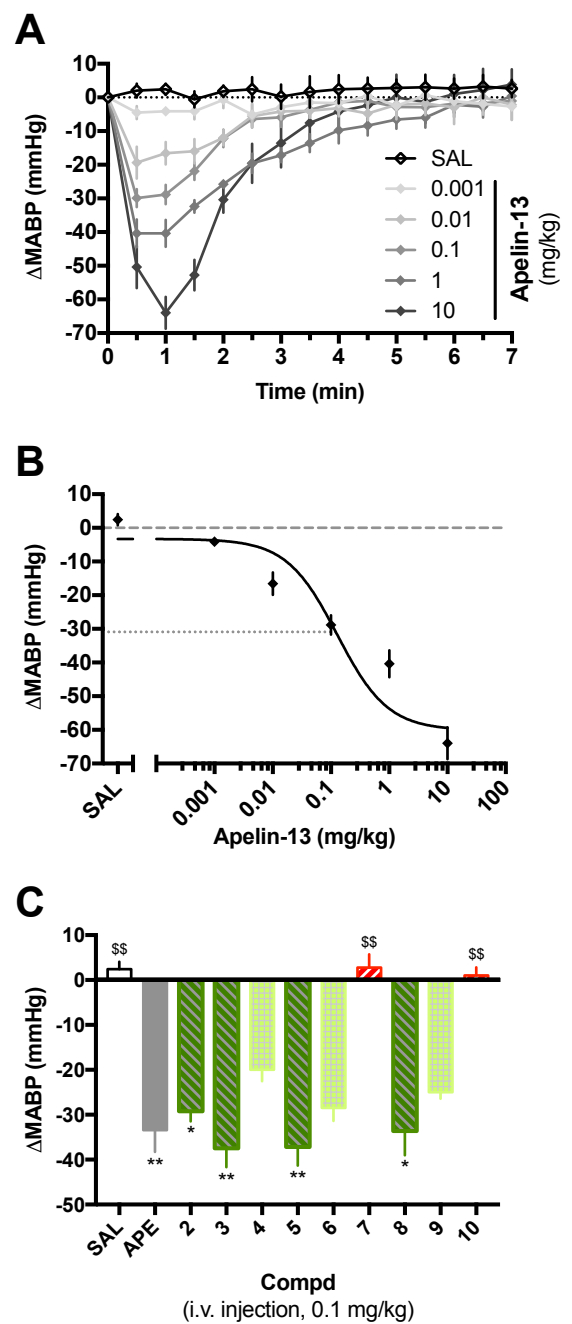

Fig. 3. Effects of apelin-13 and C-terminally modified analogs on blood pressure. (A) Effect of increasing doses of apelin-13 (i.v. injection) on the mean arterial blood pressure (MABP) of anesthetized rats, measured using non-invasive blood pressure recording. (B) Dose-response curve of apelin-13's hypotensive effects. Each point represents the maximum blood pressure drop as recorded on panel A. (C) Effect of the i.v. injection of saline (SAL, 0.1 mL/kg), apelin-13 (APE) or the analogs $(0.1 \mathrm{mg} / \mathrm{kg})$ on the MABP of anesthetized rats. Each value represents the mean \pm S.E.M. obtained with 6-8 rats. Statistical analysis was performed on the $\triangle \mathrm{MABP}$ values using the 
This is the accepted (postprint) version of the following article: Besserer-Offroy É, et al. (2018), Pharmacol Res. doi: 10.1016/j.phrs.2018.02.032, which has been accepted and published in its final form at https://www.sciencedirect.com/science/article/pii/S1043661817313804

Kruskal-Wallis multiple comparisons followed by a Dunn's post-hoc test. ${ }^{*} p<0.05, * * p<0.01$ compared to saline; $\$ p<0.01$ compared to apelin-13. 

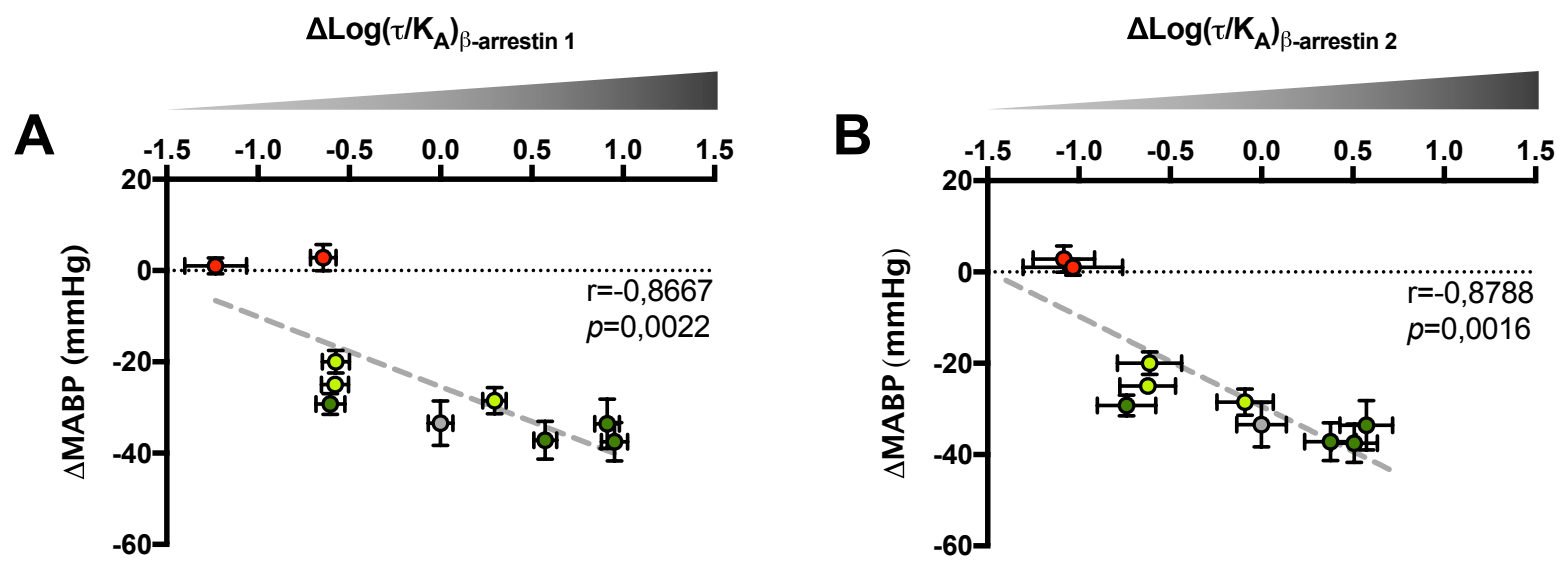

Fig. 4. Correlations between the hypotensive effect and the relative efficacy of $\beta$ arr recruitment. (A) Correlation between the $\triangle \mathrm{MABP}$ and the normalized transduction coefficient

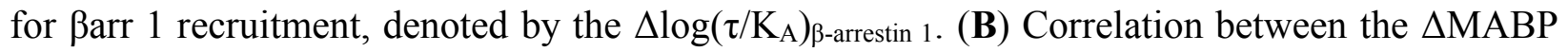
and the normalized transduction coefficient for $\beta$ arr 2 recruitment, denoted by the $\Delta \log \left(\tau / K_{A}\right)_{\beta-}$ arrestin 2. Each point represents the mean \pm S.E.M. of the $\triangle \mathrm{MABP}$ in the $\mathrm{y}$-axis and the S.E.M. of the $\Delta \log \left(\tau / \mathrm{K}_{\mathrm{A}}\right)$ in the $\mathrm{x}$-axis. Colors denote the ability to induce a hypotensive response, red dots represent analogs statistically different from apelin-13, light green dots represent analogs not statistically different from saline or apelin-13, and dark green dots represent analogs statistically different from saline. The gray dot represents the reference compound apelin-13 as represented in Fig. 3C. Statistical analysis was performed using the Spearman correlation; $r$ coefficient and $p$ values are reported on each graph, a $p<0.05$ was considered significant.

(c) 2018. This manuscript version is made available under the license http://creativecommons.org/licenses/by-nc-nd/4.0/ 
This is the accepted (postprint) version of the following article: Besserer-Offroy É, et al. (2018), Pharmacol Res. doi: 10.1016/j.phrs.2018.02.032, which has been accepted

and published in its final form at

\begin{tabular}{|c|c|c|c|c|c|c|c|}
\hline \multirow[b]{2}{*}{ Analog } & \multirow[b]{2}{*}{ sequence } & \multirow{2}{*}{$\begin{array}{c}\text { binding } \\
\mathrm{IC}_{50}(\mathrm{nM})^{\mathrm{a}}\end{array}$} & \multicolumn{5}{|c|}{ functional assays $^{b}$} \\
\hline & & & $\begin{array}{c}\mathrm{cAMP}_{\mathrm{i}} \\
\mathrm{EC}_{50}(\mathrm{nM})^{\mathrm{c}}\end{array}$ & $\begin{array}{c}\mathrm{G} \alpha_{\mathrm{il}} \\
\mathrm{EC}_{50}(\mathrm{nM})\end{array}$ & $\begin{array}{c}\mathrm{G}_{\mathrm{oA}_{\mathrm{A}}} \\
\mathrm{EC}_{50}(\mathrm{nM})\end{array}$ & $\begin{array}{c}\text { Barr 1 } \\
\mathrm{EC}_{50}(\mathrm{nM})\end{array}$ & $\begin{array}{c}\text { Barr 2 } \\
\mathrm{EC}_{50}(\mathrm{nM})\end{array}$ \\
\hline 1 & apelin-13 & $1.2 \pm 0.1$ & $1.8 \pm 0.4$ & $0.39 \pm 0.07$ & $6.2 \pm 1.4$ & $24 \pm 1.4$ & $52 \pm 13$ \\
\hline 2 & {$\left[\mathrm{Nle}^{11}, \mathrm{Val}^{13}\right]$ apelin-13 } & $18.2 \pm 3.2$ & $6.9 \pm 3.4$ & $0.52 \pm 0.03$ & $3.4 \pm 1.1$ & $81 \pm 3$ & $232 \pm 99$ \\
\hline 3 & {$\left[\mathrm{Nle}^{11}, \mathrm{Phe}(4-\mathrm{Me})^{13}\right]$ apelin-13 } & $0.25 \pm 0.02$ & $0.13 \pm 0.01$ & $0.56 \pm 0.02$ & $3.0 \pm 1.5$ & $3.4 \pm 1.5$ & $33 \pm 26$ \\
\hline 4 & {$\left[\mathrm{Nle}^{11},\left(2\right.\right.$-pyridyl)Ala $\left.{ }^{13}\right]$ apelin-13 } & $6.1 \pm 1.0$ & $4.8 \pm 2.5$ & $0.32 \pm 0.05$ & $2.2 \pm 0.6$ & $18 \pm 5.9$ & $35 \pm 6.8$ \\
\hline 5 & {$\left[\mathrm{Nle}^{11}, \operatorname{Tyr}(\mathrm{OBn})^{13}\right]$ apelin-13 } & $0.02 \pm 0.003$ & $0.31 \pm 0.16$ & $0.49 \pm 0.21$ & $1.5 \pm 0.5$ & $7.2 \pm 2.6$ & $14 \pm 5.5$ \\
\hline 6 & {$\left[\mathrm{Nle}^{11}, \mathrm{Bpa}^{13}\right]$ apelin-13 } & $0.48 \pm 0.05$ & $0.06 \pm 0.01$ & $0.64 \pm 0.30$ & $4.0 \pm 2.0$ & $13 \pm 3.4$ & $38 \pm 10$ \\
\hline 7 & {$\left[\mathrm{Nle}^{11}\right.$, AnthranylAla $\left.{ }^{13}\right]$ apelin-13 } & $13.7 \pm 1.6$ & $217 \pm 51$ & $2.14 \pm 0.18$ & $5.1 \pm 1.3$ & $133 \pm 10$ & $628 \pm 223$ \\
\hline 8 & {$\left[\mathrm{Nle}^{11},(L-\alpha-\mathrm{Me}) \mathrm{Phe}^{13}\right]$ apelin-13 } & $0.43 \pm 0.03$ & $0.09 \pm 0.03$ & $2.32 \pm 0.85$ & $3.6 \pm 1.5$ & $3.2 \pm 1.8$ & $15 \pm 7.0$ \\
\hline 9 & {$\left[\mathrm{Nle}^{11}\right.$, PheGly $\left.^{13}\right]$ apelin-13 } & $14.3 \pm 1.4$ & $2.4 \pm 0.4$ & $1.62 \pm 0.20$ & $10.3 \pm 3.9$ & $102 \pm 24$ & $247 \pm 160$ \\
\hline 10 & {$\left[\mathrm{Ala}^{13}\right]$ apelin-13 } & $68.2 \pm 15$ & $8.84 \pm 1.3$ & $2.41 \pm 0.97$ & $1.9 \pm 0.6$ & $425 \pm 303$ & $154 \pm 98$ \\
\hline
\end{tabular}

${ }^{a}$ Values of binding are from [19]. IC 50 values represent the concentration of ligand inhibiting $50 \%$ of the radioligand binding. ${ }^{b} E C_{50}$ values represent the concentration of ligand showing 50\% of pathway's activation. ${ }^{c} \mathrm{cAMP}$ i refers to the inhibition of the forskolin-induced cAMP production. 
This is the accepted (postprint) version of the following article: Besserer-Offroy É, et al. (2018), Pharmacol Res. doi: 10.1016/j.phrs.2018.02.032, which has been accepted https://www.sciencedirect.com/science/article/pii/S1043661817313804

Table 1. Binding affinity and $\mathrm{G \alpha}_{\mathrm{i} / \mathrm{o}}, \mathrm{cAMP}$ inhibition, and $\beta$ arr recruitment potencies of C-terminally modified apelin-13 analogs.

Each value represents the mean of three independent experiments, which were each done in triplicate, and is expressed as the mean \pm S.E.M. 
This is the accepted (postprint) version of the following article: Besserer-Offroy É, et al. (2018), Pharmacol Res. doi: 10.1016/j.phrs.2018.02.032, which has been accepted

\begin{tabular}{|c|c|c|c|c|c|c|c|c|c|c|}
\hline \multirow{2}{*}{ Analog } & \multicolumn{2}{|c|}{$\mathrm{cAMP}_{\mathrm{i}}{ }^{\mathrm{a}}$} & \multicolumn{2}{|c|}{$G \alpha_{i 1}$} & \multicolumn{2}{|c|}{$\mathrm{G} \alpha_{\mathrm{oA}}$} & \multicolumn{2}{|c|}{ ßarr 1} & \multicolumn{2}{|c|}{ ßarr 2} \\
\hline & $\Delta \log \left(\tau / \mathrm{K}_{\mathrm{A}}\right)$ & $\mathrm{RE}$ & $\Delta \log \left(\tau / \mathrm{K}_{\mathrm{A}}\right)$ & $\mathrm{RE}$ & $\Delta \log \left(\tau / \mathrm{K}_{\mathrm{A}}\right)$ & $\mathrm{RE}$ & $\Delta \log \left(\tau / \mathrm{K}_{\mathrm{A}}\right)$ & $\mathrm{RE}$ & $\Delta \log \left(\tau / \mathrm{K}_{\mathrm{A}}\right)$ & $\mathrm{RE}$ \\
\hline 1 & $0.00 \pm 0.07$ & 1.00 & $0.00 \pm 0.22$ & 1.00 & $0.00 \pm 0.26$ & 1.00 & $0.00 \pm 0.07$ & 1.00 & $0.00 \pm 0.14$ & 1.00 \\
\hline 2 & $-0.61 \pm 0.11$ & 0.25 & $-0.60 \pm 0.25$ & 0.25 & $1.01 \pm 0.26$ & 10.26 & $-0.60 \pm 0.08$ & 0.25 & $-0.74 \pm 0.16$ & 0.18 \\
\hline 3 & $0.68 \pm 0.11$ & 4.81 & $-0.16 \pm 0.24$ & 0.70 & $1.09 \pm 0.26$ & 12.39 & $0.95 \pm 0.07$ & 8.95 & $0.51 \pm 0.13$ & 3.22 \\
\hline 4 & $0.05 \pm 0.14$ & 1.12 & $-0.45 \pm 0.23$ & 0.36 & $0.32 \pm 0.25$ & 2.09 & $-0.57 \pm 0.07$ & 0.27 & $-0.61 \pm 0.18$ & 0.24 \\
\hline 5 & $0.45 \pm 0.11$ & 2.85 & $-0.14 \pm 0.22$ & 0.72 & $0.91 \pm 0.26$ & 8.09 & $0.57 \pm 0.06$ & 3.74 & $0.38 \pm 0.14$ & 2.38 \\
\hline 6 & $1.71 \pm 0.09$ & 51.40 & $-0.09 \pm 0.22$ & 0.81 & $0.62 \pm 0.27$ & 4.14 & $0.30 \pm 0.06$ & 1.97 & $-0.09 \pm 0.15$ & 0.81 \\
\hline 7 & $-2.09 \pm 0.14$ & 0.01 & $-0.86 \pm 0.24$ & 0.14 & $0.38 \pm 0.26$ & 2.40 & $-0.64 \pm 0.07$ & 0.23 & $-1.08 \pm 0.17$ & 0.08 \\
\hline 8 & $1.37 \pm 0.12$ & 23.5 & $-0.62 \pm 0.25$ & 0.24 & $0.46 \pm 0.26$ & 2.88 & $0.91 \pm 0.07$ & 8.17 & $0.57 \pm 0.14$ & 3.75 \\
\hline 9 & $-0.32 \pm 0.11$ & 0.47 & $-0.87 \pm 0.23$ & 0.13 & $0.04 \pm 0.25$ & 1.10 & $-0.58 \pm 0.07$ & 0.26 & $-0.62 \pm 0.15$ & 0.24 \\
\hline 10 & $-0.86 \pm 0.10$ & 0.14 & $-0.54 \pm 0.29$ & 0.29 & $1.64 \pm 0.26$ & 43.75 & $-1.23 \pm 0.17$ & 0.06 & $-1.03 \pm 0.27$ & 0.09 \\
\hline
\end{tabular}

${ }^{a}$ cAMP refers to the inhibition of the forskolin-induced cAMP production.

Table 2. Normalized transduction coefficient $\left(\Delta \log \left(\tau / \mathrm{K}_{\mathrm{A}}\right)\right)$ and relative efficacy $(\mathrm{RE})$ of $\mathrm{C}$-terminally modified apelin-13 analogs.

Each value represents the mean of three independent experiments, done in triplicate, and expressed as the mean \pm S.E.M. 


\title{
The hypotensive effect of activated apelin receptor is correlated with
}

$\beta$-arrestin recruitment

\section{Supporting Information}

Élie Besserer-Offroy ${ }^{\mathrm{a}, \mathrm{c}, \mathrm{ORCID} \text { ID }}$, Patrick Bérubéa,c, Jérôme Côtéa, ${ }^{\mathrm{a}, \mathrm{c}}$, Alexandre Murza ${ }^{\mathrm{a}, \mathrm{c}}$, Jean-Michel Longpréa,c, Robert Dumaine $^{\mathrm{a}}$, Olivier Lesur ${ }^{\mathrm{b}, \mathrm{c}}$, Mannix Auger-Messier ${ }^{\mathrm{b}, \text { ORCID ID }}$, Richard Leduc $^{\mathrm{a}, \mathrm{c}, \text { ORCID ID }}$, Éric Marsault $\mathrm{a}^{\mathrm{a}, \mathrm{c}, *, \underline{\mathrm{ORCID}} \text { ID }}$, Philippe Sarret ${ }^{\mathrm{a}, \mathrm{c} *}$

\author{
Affiliations \\ ${ }^{a}$ Department of Pharmacology-Physiology, Faculty of Medicine and Health Sciences, Université \\ de Sherbrooke, Sherbrooke, Québec, CANADA J1H 5N4 \\ b Department of Medicine, Faculty of Medicine and Health Sciences, Université de Sherbrooke, \\ Sherbrooke, Québec, CANADA J1H 5N4 \\ c Institut de pharmacologie de Sherbrooke, Université de Sherbrooke, Sherbrooke, Québec, \\ CANADA J1H 5N4
}

*To whom correspondence should be addressed

(c) 2018. This manuscript version is made available under the CC-BY-NC-ND 4.0 license http://creativecommons.org/licenses/by-nc-nd/4.0/ 


\section{TABLE OF CONTENT}

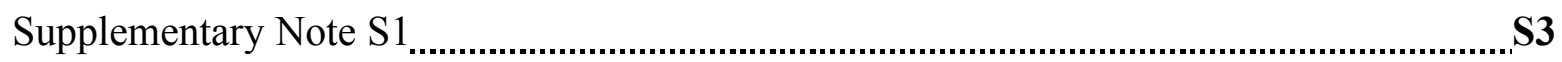

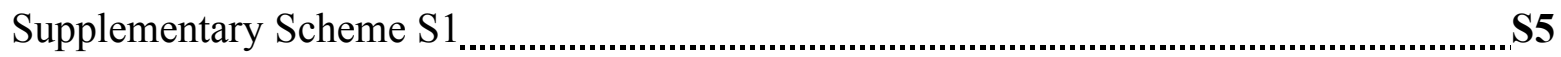

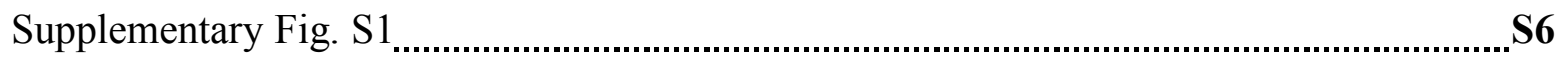

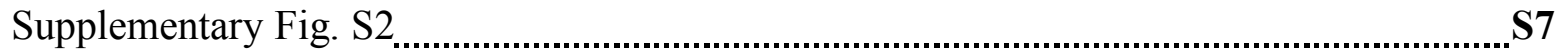

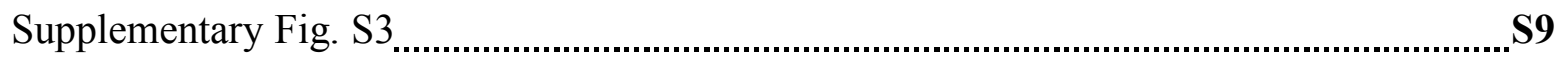

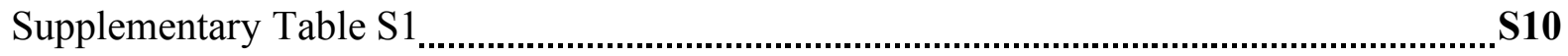

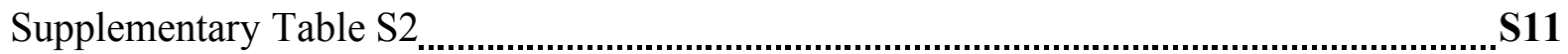

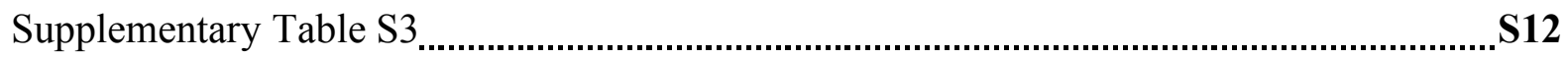

(C) 2018. This manuscript version is made available under the CC-BY-NC-ND 4.0 


\section{Supplementary Note S1. Fittings parameters and equations to retrieve ligand-specific parameters of receptor activation using GraphPad Prism.}

Selection of the reference agonist: Any ligand could be defined as the reference agonist providing it is a full agonist on each of the assessed pathways.

The following code is used to program a non-linear curve fit to retrieve ligand-specific parameters of receptor activation with GraphPad Prism v6 and higher:

1. Open GraphPad Prism and create a new user-define equation:

$$
\text { Go to Analyse } \stackrel{\zeta}{\longrightarrow} \text { Create new equation }+\cdot
$$

2. In the equation tab, select "Explicit Equation: $Y=$ a function of $X$ and parameters"

3. Name your new equation: "Black and Leff operational model"

4. In the definition panel enter the following:

$$
\begin{aligned}
& \text { A_T }=10^{\wedge}\left(\mathrm{X}^{*} \mathrm{n}\right)^{*} 10^{\wedge}\left(\log \mathrm{T}^{*} \mathrm{n}\right) \\
& \mathrm{Y}=\mathrm{Emax}{ }^{*} \mathrm{~A} \_\mathrm{T} /\left[\mathrm{A}_{-} \mathrm{T}+\left(10^{\wedge} \mathrm{X}+10^{\wedge} \operatorname{LogKA}\right)^{\wedge} \mathrm{n}\right]
\end{aligned}
$$

5. Go to the "Rules for Initial Values" tab and enter the following:

\begin{tabular}{ccc} 
Parameter & Value & Rule \\
\hline $\mathrm{n}$ & 2 & Initial value, to be fit \\
LogT & 0.1 & Initial value, to be fit \\
Emax & 100 & Initial value, to be fit \\
LogKA & -8 & Initial value, to be fit
\end{tabular}


Select: Start graphing the curve at the smallest $X$ value

6. Go to the "Default Constraints" tab and enter the following:

\begin{tabular}{ccc} 
Parameter & Constraint & Value \\
\hline $\mathrm{n}$ & Shared value for all dataset & - \\
$\log \mathrm{T}$ & No constraint & - \\
$\mathrm{Emax}$ & Constant equal to & 100 \\
LogKA & No constraint & -
\end{tabular}

7. Go to the "Default Constraints" tab and enter the following:

a. In "Report transforms of best-fit parameters (with 95\% CI)":

$$
\begin{array}{ll}
\mathrm{KA}=10^{\wedge} \operatorname{LogKA} & \text { CI method: Asymetrical } \\
\mathrm{T}=10^{\wedge} \log \mathrm{T} & \text { CI method: Asymetrical }
\end{array}
$$

b. In "Report these combinations of best-fit parameters (with 95\% CI)":

$$
\log (\mathrm{T} / \mathrm{KA})=\mathrm{P} 1-\mathrm{P} 2 \quad \mathrm{P} 1=\log \mathrm{T} \quad \mathrm{P} 2=\operatorname{LogKA}
$$

8. Your new custom equation is now configured. You can retrieve it under:

Analyse $>$ Nonlinear regression $>$ User-defined equation $>$ Black and Leff operational model

9. To analyze your data, create a new XY spreadsheet and enter the normalized values from your assay into column A and subsequent. Then, retrieve your custom equation and apply the analysis.

10. If curve fit does not work (Ambigous), modify the Emax constraint and enter the Emax of the reference ligand.

11. The $\log (\mathrm{T} / \mathrm{KA})$ is given directly in "results of nonlinear fit".

(C) 2018. This manuscript version is made available under the CC-BY-NC-ND 4.0 license http://creativecommons.org/licenses/by-nc-nd/4.0/ 
This is the accepted (postprint) version of the following article: Besserer-Offroy É, et al. (2018), Pharmacol Res. doi: 10.1016/j.phrs.2018.02.032, which has been accepted

and published

in final

form

at
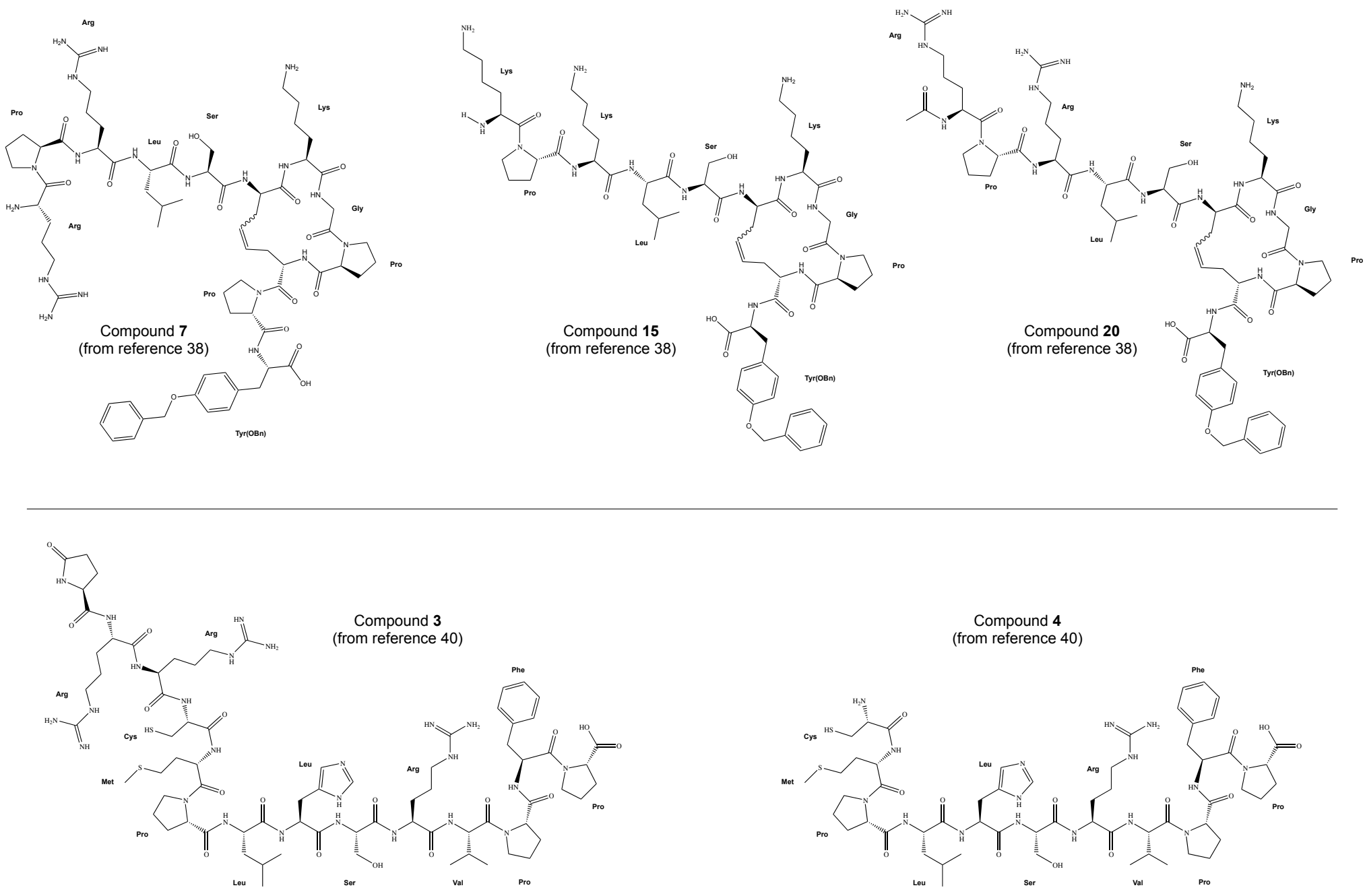

Supplementary Scheme S2. Developed formulae of compounds 7, 15, and 20 (from the reference 38) and developed formulae of compounds 3 and 4 (from the reference 40).

(c) 2018. This manuscript version is made available under the CC-BY-NC-ND 4.0 license http://creativecommons.org/licenses/by-nc-nd/4.0/ 


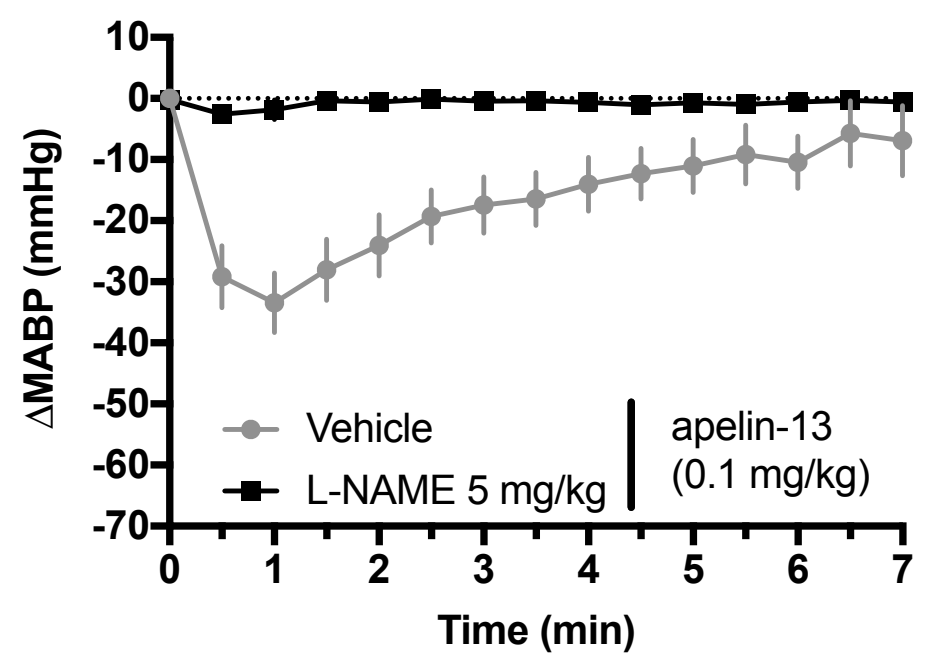

Supplementary Fig. S1. Time course of the blood pressure response triggered by the bolus injection of apelin-13 in L-NAME- or vehicle-treated rats. The grey solid line represents the effect of a $0.1 \mathrm{mg} / \mathrm{kg}$ dose of apelin-13 injected as a bolus in vehicle-treated animals. The black (filled squares) line represents the effect of a bolus injection of apelin-13 at a dose of $0.1 \mathrm{mg} / \mathrm{kg}$ in animals pre-treated with $5 \mathrm{mg} / \mathrm{kg}$ of the NO-synthase inhibitor L-NAME. Bolus injection of apelin-13 was done 15 minutes after vehicle or L-NAME treatment. Each point represents the mean \pm S.E.M. obtained with 5-8 rats. 
A

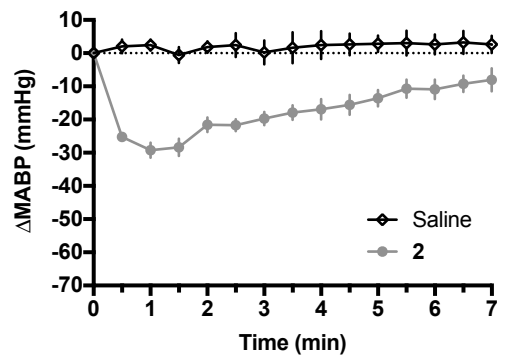

C

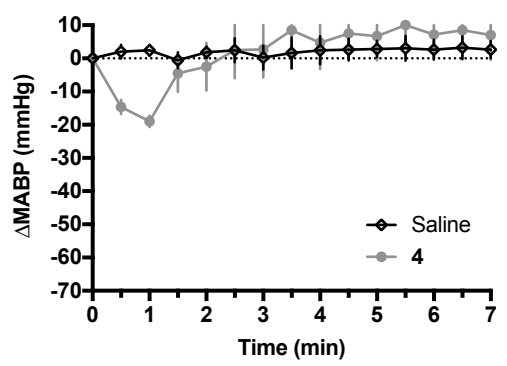

E

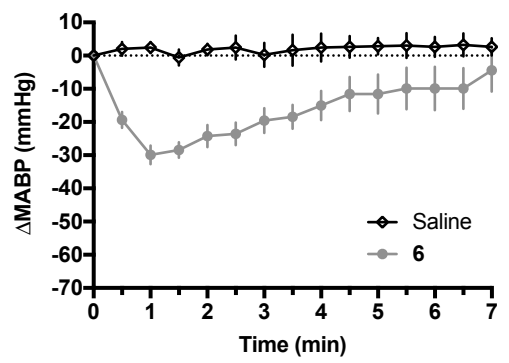

G

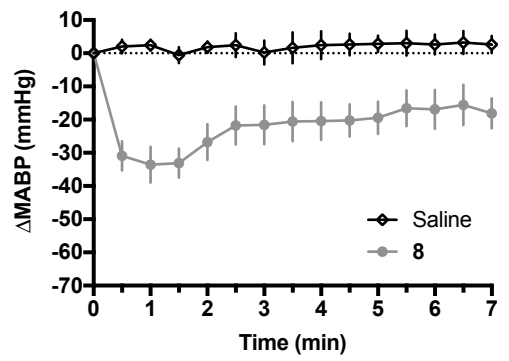

I

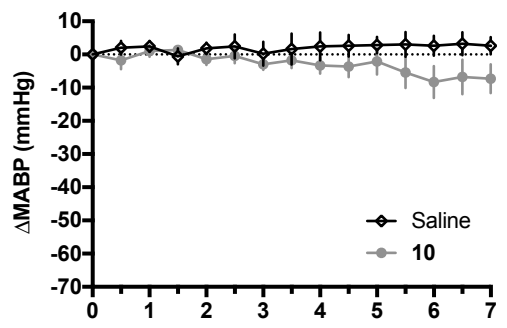

B

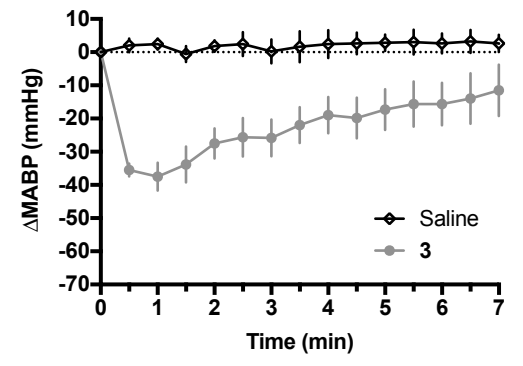

D

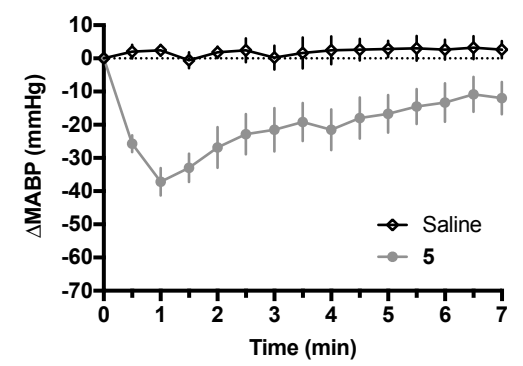

$\mathbf{F}$

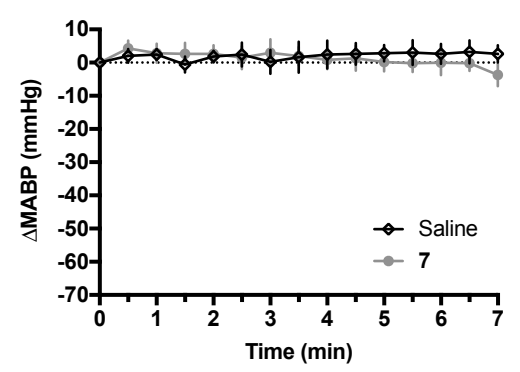

H

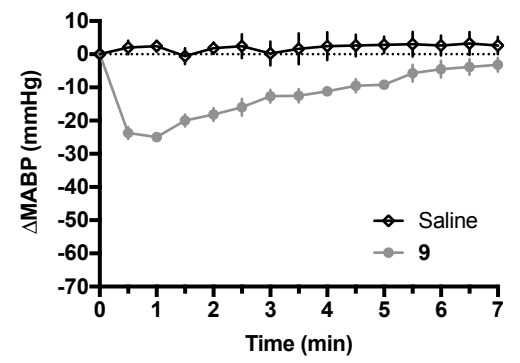

J

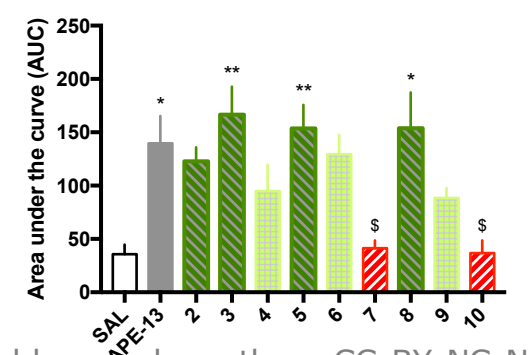

(c) 2018. This manusme(min) version is made available onder the CC-BY-NC-ND 
Supplementary Fig. S2. Time course of the blood pressure response triggered by the bolus injection of apelin-13 analogs. (A) Compound 2. (B) Compound 3. (C) Compound 4. (D) Compound 5. (E) Compound 6. (F) Compound 7. (G) Compound 8. (H) Compound 9. (I) Compound 10. The black solid line represents the effect of saline injection. (J) Area under the curve for saline injection (SAL), apelin-13 (APE-13), and each of the analogs (2-10). Each point represents the mean \pm S.E.M. obtained with 6-8 rats. Statistical analysis was performed on the AUC values using the Kruskal-Wallis multiple comparisons followed by a Dunn's post-hoc test. $* \mathrm{p}<0.05,{ }^{* *} \mathrm{p}<0.01$ compared to saline; $\$ \mathrm{p}<0.05$ compared to apelin-13. 

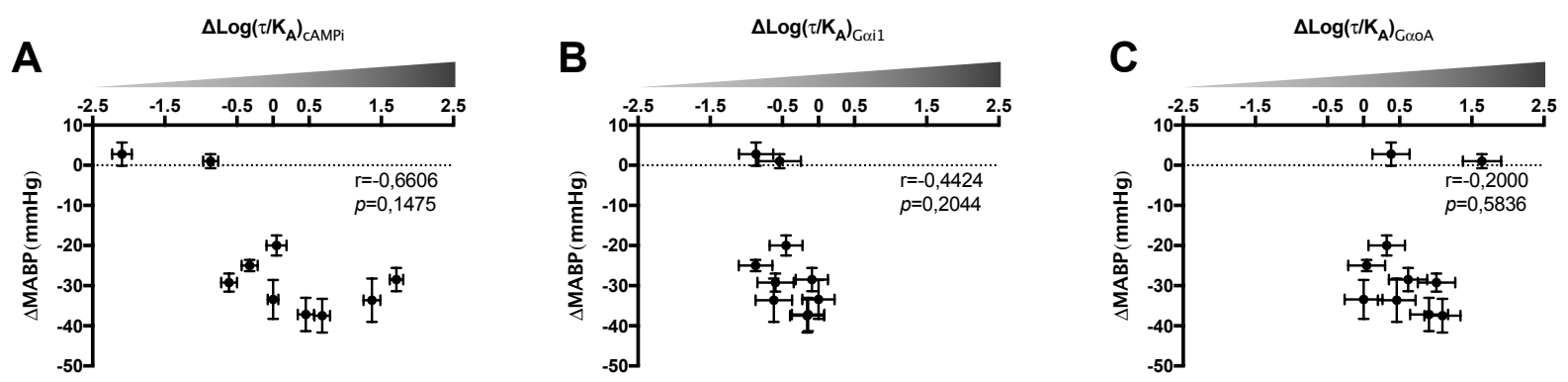

Supplementary Fig. S3. Correlations between the hypotensive effect and the efficacy to activate $\mathbf{G a}_{\mathrm{i} / \mathrm{o}}$ and $\mathrm{cAMP}$ signaling pathways. (A) Correlation between the $\triangle \mathrm{MABP}$ and the normalized transduction coefficient for the inhibition of cAMP production, denoted by the $\Delta \log (\tau / \mathrm{KA})_{\mathrm{cAMPi}}$. (B) Correlation between the $\triangle \mathrm{MABP}$ and the normalized transduction coefficient for the activation of the $\mathrm{G} \alpha_{\mathrm{i} 1}$ pathway, denoted by the $\Delta \log (\tau / \mathrm{KA})_{\mathrm{Gail}}$. (C) Correlation between the $\triangle \mathrm{MABP}$ and the normalized transduction coefficient for the activation of the $\mathrm{G} \alpha_{\mathrm{OA}}$ pathway, denoted by the $\Delta \log (\tau / \mathrm{KA})_{\mathrm{G} \alpha_{0} \mathrm{~A}}$. Each point represents the mean \pm S.E.M. of the $\Delta \mathrm{MABP}$ in the $\mathrm{y}$-axis and the S.E.M. of the $\Delta \log (\tau / \mathrm{KA})$ in the $\mathrm{x}$-axis. Statistical analyses were performed using the Spearman correlation; $r$ coefficient and $p$ values are reported on each graph. 


\section{Supplementary Table S1. Maximal efficacy $\left(E_{\max }\right)$ values of each compound on $\mathbf{G a}_{\mathrm{i} / / 0}, \mathbf{c A M P}$}

inhibition, and $\beta$-arrestin recruitment. Each value represents the mean of three independent experiments, which were each done in triplicate, and is expressed as the mean \pm S.E.M.

\begin{tabular}{|c|c|c|c|c|c|}
\hline analog & $\begin{array}{l}\mathrm{cAMP}{ }_{i}^{\mathrm{a}} \\
\mathrm{E}_{\max }(\%)\end{array}$ & $\begin{array}{c}\mathrm{G} \alpha_{\mathrm{i} 1} \\
\mathrm{E}_{\max }(\%)\end{array}$ & $\begin{array}{c}\mathrm{G} \alpha_{\mathrm{oA}} \\
\mathrm{E}_{\max }(\%)\end{array}$ & $\begin{array}{c}\beta \text {-arrestin } 1 \\
\mathrm{E}_{\max }(\%)\end{array}$ & $\begin{array}{c}\beta \text {-arrestin } 2 \\
E_{\max }(\%)\end{array}$ \\
\hline 1 & $100.0 \pm 1.42$ & $100.0 \pm 3.8$ & $100.0 \pm 1.9$ & $100.0 \pm 2.7$ & $100.0 \pm 3.5$ \\
\hline 2 & $83.7 \pm 3.0$ & $96.3 \pm 7.2$ & $104.4 \pm 6.1$ & $91.8 \pm 3.9$ & $84.6 \pm 2.4$ \\
\hline 3 & $105.1 \pm 7.7$ & $98.0 \pm 7.5$ & $111.6 \pm 8.6$ & $98.2 \pm 2.9$ & $102.6 \pm 4.9$ \\
\hline 4 & $91.7 \pm 4.4$ & $112.2 \pm 6.6$ & $108.9 \pm 6.2$ & $95.7 \pm 4.3$ & $99.2 \pm 2.2$ \\
\hline 5 & $92.0 \pm 3.5$ & $106.0 \pm 6.5$ & $99.1 \pm 4.6$ & $108.8 \pm 2.5$ & $92.9 \pm 2.3$ \\
\hline 6 & $108 \pm 3.9$ & $99.7 \pm 4.6$ & $95.6 \pm 5.1$ & $105.1 \pm 3.5$ & $93.1 \pm 2.4$ \\
\hline 7 & $84.7 \pm 9.9$ & $101.2 \pm 5.8$ & $106.6 \pm 7.0$ & $105.6 \pm 4.3$ & $76.0 \pm 3.6$ \\
\hline 8 & $89.9 \pm 2.1$ & $95.3 \pm 5.9$ & $100.3 \pm 6.1$ & $107.5 \pm 3.7$ & $92.9 \pm 2.5$ \\
\hline 9 & $97.2 \pm 2.3$ & $102.4 \pm 7.4$ & $111.8 \pm 5.2$ & $97.8 \pm 4.7$ & $88.0 \pm 3.3$ \\
\hline 10 & $101.7 \pm 3.7$ & $105.4 \pm 5.5$ & $104.2 \pm 10.3$ & $48.43 \pm 13.7$ & $47.6 \pm 9.7$ \\
\hline
\end{tabular}

(c) 2018. This manuscript version is made available under the CC-BY-NC-ND 4.0 license http://creativecommons.org/licenses/by-nc-nd/4.0/ 
Supplementary Table S2. Transduction coefficient $(\log (\tau / \mathrm{KA}))$ values of each compound on $\mathbf{G} \alpha_{\mathrm{i} / 0}$, cAMP inhibition, and $\beta$-arrestin recruitment. Each value represents the mean of three independent experiments, which were each done in triplicate, and is expressed as the mean \pm S.E.M.

\begin{tabular}{|c|c|c|c|c|c|}
\hline analog & $\begin{array}{c}\mathrm{cAMP}{ }_{\mathrm{i}}^{\mathrm{a}} \\
\log \left(\tau / \mathrm{K}_{\mathrm{A}}\right)\end{array}$ & $\begin{array}{c}\mathrm{G} \alpha_{\mathrm{i} 1} \\
\log \left(\tau / \mathrm{K}_{\mathrm{A}}\right)\end{array}$ & $\begin{array}{c}\mathrm{G} \alpha_{\mathrm{OA}} \\
\log \left(\tau / \mathrm{K}_{\mathrm{A}}\right)\end{array}$ & $\begin{array}{c}\beta \text {-arrestin-1 } \\
\log \left(\tau / \mathrm{K}_{\mathrm{A}}\right)\end{array}$ & $\begin{array}{c}\beta \text {-arrestin-2 } \\
\log \left(\tau / \mathrm{K}_{\mathrm{A}}\right)\end{array}$ \\
\hline 1 & $8.77 \pm 0.05$ & $9.05 \pm 0.15$ & $7.98 \pm 0.19$ & $7.54 \pm 0.05$ & $7.51 \pm 0.10$ \\
\hline 2 & $8.16 \pm 0.10$ & $8.46 \pm 0.19$ & $8.99 \pm 0.18$ & $6.93 \pm 0.06$ & $6.77 \pm 0.13$ \\
\hline 3 & $9.45 \pm 0.10$ & $8.90 \pm 0.17$ & $9.08 \pm 0.17$ & $8.49 \pm 0.05$ & $8.02 \pm 0.08$ \\
\hline 4 & $8.82 \pm 0.13$ & $8.60 \pm 0.16$ & $8.30 \pm 0.17$ & $6.96 \pm 0.06$ & $6.90 \pm 0.14$ \\
\hline 5 & $9.22 \pm 0.10$ & $8.91 \pm 0.16$ & $8.89 \pm 0.18$ & $8.11 \pm 0.04$ & $7.89 \pm 0.10$ \\
\hline 6 & $10.48 \pm 0.08$ & $8.96 \pm 0.16$ & $8.60 \pm 0.19$ & $7.83 \pm 0.04$ & $7.42 \pm 0.12$ \\
\hline 7 & $6.68 \pm 0.13$ & $8.19 \pm 0.18$ & $8.36 \pm 0.18$ & $6.89 \pm 0.05$ & $6.43 \pm 0.14$ \\
\hline 8 & $10.14 \pm 0.10$ & $8.43 \pm 0.20$ & $8.44 \pm 0.18$ & $8.45 \pm 0.05$ & $8.09 \pm 0.10$ \\
\hline 9 & $8.45 \pm 0.10$ & $8.18 \pm 0.17$ & $8.03 \pm 0.17$ & $6.96 \pm 0.06$ & $6.89 \pm 0.12$ \\
\hline 10 & $7.91 \pm 0.09$ & $8.51 \pm 0.25$ & $9.62 \pm 0.19$ & $6.30 \pm 0.16$ & $6.48 \pm 0.25$ \\
\hline
\end{tabular}

(c) 2018. This manuscript version is made available under the license http://creativecommons.org/licenses/by-nc-nd/4.0/ 
This is the accepted (postprint) version of the following article: Besserer-Offroy É, et al. (2018), Pharmacol Res. doi: 10.1016/j.phrs.2018.02.032, which has been accepted and published in final form at https://www.sciencedirect.com/science/article/pii/S1043661817313804

Supplementary Table S3. Normalized transduction coefficient $(\Delta \log (\tau / \mathrm{KA}))$ values and adjusted $p$ value for each compound on

$\mathbf{G \alpha}_{\mathrm{i} / \mathbf{0}}, \mathbf{c A M P}$ inhibition, and $\boldsymbol{\beta}$-arrestin recruitment. $\Delta \log (\tau / \mathrm{KA})$ values are expressed as the mean $\pm \mathrm{S}$.E.M. Adjusted $\mathrm{p}$ values result from the statistical comparison of the $\Delta \log (\tau / \mathrm{KA})$ on each pathway with a Kruskal-Wallis followed by a Dunn's post hoc test. An adjusted $p<0.05$ was considered significant. Shaded boxes represent significantly different values compared to apelin-13.

\begin{tabular}{|c|c|c|c|c|c|c|c|c|c|c|}
\hline \multirow[b]{2}{*}{ analog } & \multicolumn{2}{|c|}{$\mathrm{cAMP}_{\mathrm{i}}^{\mathrm{a}}$} & \multicolumn{2}{|c|}{$\mathrm{G} \alpha_{\mathrm{i} 1}$} & \multicolumn{2}{|c|}{$\mathrm{G} \alpha_{\mathrm{oA}}$} & \multicolumn{2}{|c|}{$\beta$-arrestin-1 } & \multicolumn{2}{|c|}{$\beta$-arrestin-2 } \\
\hline & $\Delta \log \left(\tau / \mathrm{K}_{\mathrm{A}}\right)$ & $\begin{array}{c}\text { Adjusted } \\
p \text { value }\end{array}$ & $\Delta \log \left(\tau / \mathrm{K}_{\mathrm{A}}\right)$ & $\begin{array}{c}\text { Adjusted } \\
p \text { value }\end{array}$ & $\Delta \log \left(\tau / \mathrm{K}_{\mathrm{A}}\right)$ & $\begin{array}{c}\text { Adjusted } \\
p \text { value }\end{array}$ & $\Delta \log \left(\tau / \mathrm{K}_{\mathrm{A}}\right)$ & $\begin{array}{c}\text { Adjusted } \\
p \text { value }\end{array}$ & $\Delta \log \left(\tau / \mathrm{K}_{\mathrm{A}}\right)$ & $\begin{array}{c}\text { Adjusted } \\
p \text { value }\end{array}$ \\
\hline 1 & $0.00 \pm 0.07$ & - & $0.00 \pm 0.22$ & - & $0.00 \pm 0.26$ & - & $0.00 \pm 0.07$ & - & $0.00 \pm 0.14$ & - \\
\hline 2 & $-0.61 \pm 0.11$ & 0.0002 & $-0.60 \pm 0.25$ & 0.3146 & $1.01 \pm 0.26$ & 0.0349 & $-0.60 \pm 0.08$ & 0.0001 & $-0.74 \pm 0.16$ & 0.0072 \\
\hline 3 & $0.68 \pm 0.11$ & 0.0001 & $-0.16 \pm 0.24$ & 0.9972 & $1.09 \pm 0.26$ & 0.0187 & $0.95 \pm 0.07$ & 0.0001 & $0.51 \pm 0.13$ & 0.1251 \\
\hline 4 & $0.05 \pm 0.14$ & 0.9994 & $-0.45 \pm 0.23$ & 0.6345 & $0.32 \pm 0.25$ & 0.9410 & $-0.57 \pm 0.07$ & 0.0001 & $-0.61 \pm 0.18$ & 0.0408 \\
\hline 5 & $0.45 \pm 0.11$ & 0.0098 & $-0.14 \pm 0.22$ & 0.9993 & $0.91 \pm 0.26$ & 0.0722 & $0.57 \pm 0.06$ & 0.0001 & $0.38 \pm 0.14$ & 0.3960 \\
\hline 6 & $1.71 \pm 0.09$ & 0.0001 & $-0.09 \pm 0.22$ & 0.9996 & $0.62 \pm 0.27$ & 0.3877 & $0.30 \pm 0.06$ & 0.0521 & $-0.09 \pm 0.15$ & 0.9994 \\
\hline 7 & $-2.09 \pm 0.14$ & 0.0001 & $-0.86 \pm 0.24$ & 0.0536 & $0.38 \pm 0.26$ & 0.8633 & $-0.64 \pm 0.07$ & 0.0001 & $-1.08 \pm 0.17$ & 0.0001 \\
\hline 8 & $1.37 \pm 0.12$ & 0.0001 & $-0.62 \pm 0.25$ & 0.2810 & $0.46 \pm 0.26$ & 0.7133 & $0.91 \pm 0.07$ & 0.0001 & $0.57 \pm 0.14$ & 0.0653 \\
\hline 9 & $-0.32 \pm 0.11$ & 0.1246 & $-0.87 \pm 0.23$ & 0.0495 & $0.04 \pm 0.25$ & 0.9999 & $-0.58 \pm 0.07$ & 0.0001 & $-0.62 \pm 0.15$ & 0.0361 \\
\hline 10 & $-0.86 \pm 0.10$ & 0.0001 & $-0.54 \pm 0.29$ & 0.4302 & $1.64 \pm 0.26$ & 0.0001 & $-1.23 \pm 0.17$ & 0.0001 & $-1.03 \pm 0.27$ & 0.0001 \\
\hline
\end{tabular}

${ }^{a} c A M P_{i}$ refers to the inhibition of the forskolin-induced cAMP production.

(C) 2018. This manuscript version is made available under the CC-BY-NC-ND 4.0 license http://creativecommons.org/licenses/by-nc-nd/4.0/ 